\title{
Analysis of Convective Transport and Parameter Sensitivity in a Single Column Version of the Goddard Earth Observation System, Version 5, General Circulation Model
}

\author{
L. E. Ott,* J. Bacmeister, ${ }^{+}$S. Pawson, ${ }^{*}$ K. Pickering, ${ }^{\#}$ G. Stenchikov, ${ }^{@}$ M. SuArez,* \\ H. Huntrieser, \& M. Loewenstein, $* *$ J. LOPEZ, ${ }^{+}{ }^{+}$AND I. XuEREF-REMY\#\# \\ * Global Modeling and Assimilation Office, NASA GSFC, Greenbelt, Maryland \\ ${ }^{+}$Goddard Earth Sciences and Technology Center, University of Maryland, Baltimore County, Baltimore, Maryland \\ \# NASA GSFC, Greenbelt, Maryland \\ ${ }^{@}$ Department of Environmental Sciences, Rutgers, The State University of New Jersey, New Brunswick, New Jersey \\ \& Institut für Physik der Atmosphäre, Deutsches Zentrum für Luft- und Raumfahrt, Oberpfaffenhofen, Germany \\ ** NASA ARC, Moffett Field, California \\ ++ Bay Area Environmental Research Institute, Sonoma, California \\ \#\# Institut Pierre Simon Laplace, Laboratoire des Sciences du Climat et de l'Environnement, UMR CEA/CNRS 1572, \\ Gif-sur-Yvette, France
}

(Manuscript received 29 November 2007, in final form 2 July 2008)

\begin{abstract}
Convection strongly influences the distribution of atmospheric trace gases. General circulation models (GCMs) use convective mass fluxes calculated by parameterizations to transport gases, but the results are difficult to compare with trace gas observations because of differences in scale. The high resolution of cloudresolving models (CRMs) facilitates direct comparison with aircraft observations. Averaged over a sufficient area, CRM results yield a validated product directly comparable to output from a single global model grid column. This study presents comparisons of vertical profiles of convective mass flux and trace gas mixing ratios derived from CRM and single column model (SCM) simulations of storms observed during three field campaigns. In all three cases, SCM simulations underpredicted convective mass flux relative to CRM simulations. As a result, the SCM simulations produced lower trace gas mixing ratios in the upper troposphere in two of the three storms than did the CRM simulations.

The impact of parameter sensitivity in the moist physics schemes employed in the SCM has also been examined. Statistical techniques identified the most significant parameters influencing convective transport. Convective mass fluxes are shown to be strongly dependent on chosen parameter values. Results show that altered parameter settings can substantially improve the comparison between SCM and CRM convective mass flux. Upper tropospheric trace gas mixing ratios were also improved in two storms. In the remaining storm, the SCM representation of $\mathrm{CO}_{2}$ was not improved because of differences in entrainment and detrainment levels in the CRM and SCM simulations.
\end{abstract}

\section{Introduction}

Convective transport profoundly affects both vertical and horizontal distributions of trace gases in the atmosphere. Updrafts associated with convective clouds can rapidly transport species from the boundary layer to the middle and upper troposphere where atmospheric residence times are increased and horizontal winds are stronger. As a result, trace gases may be transported

Corresponding author address: Lesley Ott, Global Modeling and Assimilation Office, Code 610.1, Goddard Space Flight Center, Greenbelt, MD 20771.

E-mail: lesley.e.ott@nasa.gov greater distances from source regions than if they remained in the boundary layer (e.g., Dickerson et al. 1987; Pickering et al. 1996; Bey et al. 2001). Stenchikov et al. (1996) showed that mixing across the tropopause resulting from strong convective events can alter the composition of both the upper troposphere and lower stratosphere. For global models of the atmosphere to realistically simulate trace gas distributions, convective processes must be adequately represented. General circulation models (GCMs) and global chemistrytransport models (CTMs) use convective mass fluxes calculated by convective parameterizations to transport trace gases, but the results can be difficult to evaluate owing to a lack of information about the chemical 
environment within clouds. Satellite observations are limited by resolution as well as an inability to see through clouds. Aircraft observations obtained during field projects provide valuable information on the vertical distribution of trace gases in convective clouds but are difficult to relate to global models because of differences in scale.

Cloud-resolving models (CRMs) have the potential to bridge the gap between aircraft measurements, which are taken with a high temporal $(\sim 1 \mathrm{~s})$ and spatial resolution $(\sim 100 \mathrm{~m})$, and global model grid cells, which may be hundreds of kilometers wide. Interpreting aircraft observations taken in the vicinity of convective clouds requires an understanding of when and where in relation to the storm the observations were taken. Inand out-of-cloud observations may represent significantly different chemical environments due to convective updrafts, wet scavenging, and cloud-perturbed photolysis rates (Madronich 1987). Even at a constant altitude within a convective cloud, aircraft observations of trace gas mixing ratios may exhibit large variations depending on the region of the cloud sampled. Observations of gases emitted near the surface are typically greatest in the updraft core region where the least mixing with environmental air has occurred, while observations taken in the storm anvil represent air parcels that have experienced a greater degree of dilution. This spatial distribution is evident in CRM studies of convective transport by Ott et al. (2007) and Barth et al. (2007a). Transport calculated by CRMs can be validated by comparing in-cloud chemical measurements with model output sampled in regions of the domain that best represent the time and location of observation. For example, in a CRM intercomparison study by Barth et al. (2007b), two constant altitude anvil transects were used to compare observations with model results; DeCaria et al. (2005) sampled model output within a $1600 \mathrm{~km}^{2}$ region downwind of the storm core for comparison with data collected during a spiraling aircraft ascent through an anvil. In addition to providing detailed information about trace gas distributions in the regions sampled, CRMs also provide information on regions that were not sampled or for which observations may be sparse. Unlike CRMs, a GCM employing a parameterized representation of convection is not capable of providing realistic distributions of trace gases within clouds, which makes direct comparison with aircraft observations difficult.

In this work, we seek to better understand the transport of trace gases by parameterized convection through comparison of results from single-column model (SCM) and CRM simulations. The meteorological and thermodynamic properties of convection in GCMs have been studied by comparing CRM simulations with results from a SCM version of a parent GCM (e.g.,
Bechtold et al. 2000; Ryan et al. 2000; Luo et al. 2006). This paper extends that technique to evaluate trace gas distributions produced by a SCM against three reference CRM simulations. CRM results are first compared to radar observations and, when available, observations of vertical velocity to ensure that the CRM is able to reasonably represent the major dynamical features of the observed storm including structure, evolution, cloud top height, and up- and downdraft speeds. The ability of the CRM to reproduce the in-cloud chemical environment is examined by comparing aircraft observations with model output sampled in regions of the cloud that best represent the areas in which flights were conducted (Ott et al. 2007). Once it has been determined that the CRM simulation reasonably represents both the dynamical and chemical evolution of the observed storm, CRM output is averaged over an area comparable to a global model grid cell $(150 \mathrm{~km} \times 150 \mathrm{~km})$ and compared with $\mathrm{SCM}$ results to evaluate trace gas and convective mass flux profiles produced by the SCM.

While CRMs are able to resolve the major features of observed convective events, it is important to note that they do not provide a perfect representation of reality. At typical CRM resolutions of 1-2 km, subgrid-scale microphysical and turbulent processes must be parameterized. An intercomparison study by Redelsperger et al. (2000) compared simulations of a squall line by eight CRMs and found that both the updraft structure and the horizontal and vertical extent of the simulated convection were dependent on the models' differing treatments of ice phase processes. A CRM intercomparison study by Barth et al. (2007b) focusing on convective transport of trace gases also found that simulated storm structure was strongly influenced by the representation of microphysical processes. Despite uncertainty in some of the processes represented by CRMs, a number of studies have used CRM simulations as a guide to develop parameterizations for large-scale models (e.g., Xu and Randall 1996; Tompkins 2002) and to evaluate existing parameterizations (e.g., Gregory and Miller 1989; Xu and Arakawa 1992) because they provide information about quantities and phenomena that are not observable. In this study, we use CRM simulations as a reference to better understand trace gas transport by parameterized convection. These simulations provide information on the chemical environment throughout an area equivalent to a global model grid cell, which is not available from sparse aircraft measurements, in addition to providing convective mass fluxes, which cannot be observed.

In addition to presenting comparisons of convective transport in SCM and CRM simulations, we investigate the impact of parameter sensitivity in the SCM's moist 
physics on simulated trace gas distributions and use a statistical analysis to identify the parameters whose values exert the greatest control on convective mass flux. The SCM evaluated here is from a version of the Goddard Earth Observing System, version 5 (GEOS-5) GCM, which includes the relaxed Arakawa-Schubert (RAS) convection code (Moorthi and Suarez 1992) with microphysics. Bacmeister et al. (2006) showed the importance of parameter settings in this module in determining precipitation patterns in a GCM. The impact on trace gas profiles has not previously been examined. The parameters that exert the greatest influence on convective transport of trace gases are identified using an adaptation of statistical techniques presented in Liu et al. (2004). Monte Carlo SCM simulations with varying parameter settings are ranked on the basis of their ability to reproduce mass fluxes computed from the reference CRM simulations. The simulations are divided into two groups: one group consisting of simulations that provide the most favorable comparison with the CRM and the other group containing the remaining simulations. Sensitive parameters are identified by analyzing the difference in parameter distributions between the two groups.

Section 2 of this paper provides background on the models used in these studies. In section 3, the CRM and SCM simulations of three thunderstorms observed during different field projects are described. Section 4 describes the method and results of a parameter sensitivity analysis, and section 5 presents a summary and conclusions that may be drawn from this work.

\section{Models}

\section{a. Cloud-resolving models}

Two thunderstorms were simulated using the 3D Goddard Cumulus Ensemble (GCE) model (Tao and Simpson 1993; Tao et al. 2003a) and a third with the NASA Goddard version of the nonhydrostatic fifthgeneration Pennsylvania State University-National Center for Atmospheric Research Mesoscale Model (MM5; Tao et al. 2003b) run in cloud-resolving mode. All simulations were conducted employing a $2-\mathrm{km}$ horizontal and a $0.5-\mathrm{km}$ vertical resolution. The domain for the two GCE simulations was $360 \mathrm{~km} \times 328 \mathrm{~km}$ and the domain for the MM5 simulation was $360 \mathrm{~km} \times 360$ $\mathrm{km}$. GCE simulations employ the open boundary conditions of Klemp and Wilhelmson (1978) at the lateral boundaries. In the MM5 simulation boundary conditions derived from NCEP Eta model fields were updated at 3-h intervals.

Output from the GCE and MM5 were used to drive a 3D Cloud-Scale Chemical Transport Model (CSCTM) developed at the University of Maryland and fully detailed in DeCaria (2000) and DeCaria et al. (2005). Temperature, density, wind, hydrometeor (rain, snow, graupel, cloud water, and cloud ice), and diffusion coefficient fields from the cloud model simulation are read into the CSCTM every 5 or 10 minutes in the simulation, and these fields are then interpolated to the model time step of $15 \mathrm{~s}$. The transport of chemical tracers is calculated using a van Leer advection scheme. Out-of-cloud aircraft observations are used to define profiles of trace gases prior to the onset of convection. These measurements are typically taken during the aircraft ascent and descent as well as during portions of the flight conducted in clear air in regions undisturbed by the convection. Because the background chemical environment can change substantially over the course of a day, observations used to construct initial conditions are taken within a few hours of the onset of convection.

\section{b. GEOS-5 SCM}

The GEOS-5 AGCM is a central component of the GEOS-5 atmospheric data assimilation system (Rienecker et al. 2007), where it is used for meteorological analysis and forecasting (Zhu and Gelaro 2008). It is also being adapted as a tool for studying composition and climate, for which an understanding of transport is required. The moist processes in GEOS-5 include a convective parameterization and prognostic cloud scheme, which are fully detailed in Bacmeister (2005). Convection is parameterized using the relaxed Arakawa-Schubert (RAS) scheme of Moorthi and Suarez (1992), a modified version of the Arakawa-Schubert scheme (Arakawa and Schubert 1974) in which the atmosphere is relaxed toward equilibrium. RAS represents convection as a sequence of linearly entraining plumes whose bases are defined as the lifting condensation level but which detrain at different levels. All levels between the cloud base and $100 \mathrm{hPa}$ are tested for the possibility of convection. The cloud-base mass flux is calculated for each plume using a convective available potential energy based closure. On the basis of the cloud-base mass flux, the environmental temperature and moisture profiles are modified by each plume with the subsequent plumes receiving the modified sounding to represent the interaction between clouds of different heights that might coexist within the area covered by a typical GCM grid cell.

RAS calculates profiles of convective ice and liquid condensate within supersaturated plumes by reducing humidity by the amount necessary to achieve saturation. The prognostic cloud scheme contained in GEOS-5 calculates large-scale ice and liquid condensate by assuming a probability distribution function (pdf) of total 
water. Condensate is removed from the domain by evaporation, autoconversion of liquid condensate, sedimentation of frozen condensate, and accretion of condensate by falling precipitation. The moist physics scheme recognizes three distinct types of precipitation or "showers"-precipitation 1) contained within convective updrafts, 2)originating from convective anvil clouds, and 3) originating from nonconvective largescale clouds. Owing to the complicated subgrid geometry of convective clouds, the evolution of precipitation in these settings is difficult to parameterize in a GCM. In an effort to capture this complexity, we have introduced several "tunable" parameters to the rain evaporation scheme in the model. CNV_ENVF specifies a fraction of convective precipitation that is assumed to fall through the environment and may thus be exposed to evaporation in unsaturated environmental air. The area parameters CNV_BETA and ANV_BETA relate a diagnosed updraft or cloud areal fraction to an areal fraction of precipitation. This controls the diagnosed intensity of precipitation and, thereby, microphysical parameters derived from the Marshall-Palmer size distribution. Finally, an ad hoc, bulk scaling-BASE_ EVAP_FAC - with a value from 0 to 1 is applied to the estimated evaporation of large-scale, anvil, and convective precipitation.

The GEOS-5 SCM includes the same physical parameterizations and treatment of moist processes as the 3D AGCM. In these studies, the convective transport of tracer species is calculated online. Because RAS modifies the large-scale environment by successively modifying profiles of temperature, moisture, and trace gases based on diagnosed plume mass flux, in- and out-ofcloud properties are not treated separately. The highly idealized plumes in RAS are assumed to detrain fully into a single model layer and are not analogous to convective cells visible in CRM simulations or radar observations. Cloud-scale modeling studies of convective transport that include vertical cross sections through convective cores and anvils (e.g., Ott et al. 2007; Lopez et al. 2006; Barth et al. 2007a) indicate detrainment at a broader array of altitudes than can be represented by individual RAS plumes. Although the collective impact of the plume ensemble in RAS reasonably adjusts environmental temperature and moisture profiles, as demonstrated in a number of modeling studies (e.g., Moorthi and Suarez 1992; Bacmeister et al. 2006), properties of individual plumes are likely unrealistic. Future research will focus on attempting to extract information on subgrid-scale variability of trace gases using modifications to the RAS scheme. Turbulent mixing in the boundary layer is computed using the Lock et al. (2000) scheme in unstable conditions or when a cloud-topped boundary layer exists. In other conditions, the first-order scheme of Louis (1979) is applied.

SCM simulations of storms were initialized with profiles of temperature, wind, and moisture. To ensure consistency with the CRM simulated meteorology, these profiles were calculated by averaging CRM output over a $150 \mathrm{~km} \times 150 \mathrm{~km}$ region of the domain in which convection occurred. The location of the averaging box was chosen so that it would contain the convective activity of interest throughout its lifetime. Profiles of horizontal and vertical advective tendencies of temperature, moisture, and tracer mixing ratios were also computed from CRM output, following the method of Waliser et al. (2002), and used to force the SCM. Vertical advective tendencies, which represent the impact of large-scale vertical motion on the SCM domain, were computed by subtracting a quantity representing the contribution of small-scale vertical motions, such as those found in convective regions from an area-mean quantity (Waliser et al. 2002). The equations for horizontal and vertical advective forcing of tracers, shown below, are identical in form to those provided by Waliser et al. for water vapor:

$$
\begin{aligned}
& \left(\frac{\partial C}{\partial t}\right)_{H}=\overline{\left(-u \frac{\partial C}{\partial x}-v \frac{\partial C}{\partial y}\right)} \\
& \left(\frac{\partial C}{\partial t}\right)_{V}=-\left(\overline{\left.w \frac{\partial C}{\partial z}\right)-\left(\overline{\left.-\frac{1 \partial\left(\rho C^{\prime} w^{\prime}\right)}{\partial}\right)}\right.}\right)
\end{aligned}
$$

where $C$ denotes tracer mixing ratio, $u$ and $v$ represent the horizontal wind components, $w$ represents the vertical wind, and $\rho$ is air density. The subscripts $H$ and $V$ denote the horizontal and vertical advective tendency equations; primes indicate the deviation from the areamean quantity.

The horizontal resolution of the SCM is dictated by the area over which initial and forcing conditions were computed-in this study $150 \mathrm{~km} \times 150 \mathrm{~km}$. There are 40 vertical levels including 8 below $850 \mathrm{hPa}$. All storms were simulated with a time step of $30 \mathrm{~min}$ in the SCM.

While the requirement that the $150 \mathrm{~km} \times 150 \mathrm{~km}$ averaging box contain the convective activity restricts the area of the CRM domain considered, multiple box locations are possible. We used an ensemble methodology to evaluate the impact of the choice of box location on the CRM and SCM comparisons. The locations of ten averaging boxes were chosen at random from the region of the CRM domain described above. These boundaries were used to create initial condition and advective tendency profiles for temperature, moisture, and trace gases. The SCM was run for each of the 
10 box locations and the vertically integrated convective mass flux calculated for each simulation. In the SCM simulations of storms observed during the StratosphereTroposphere Experiment: Radiation, Aerosols, and Ozone (STERAO) and the European Lightning Nitrogen Oxides Experiment (EULINOX) projects, the maximum deviation of an ensemble member from the ensemble mean vertically integrated mass flux was $6 \%$. The CRM mass flux calculated for different box locations in these storms showed negligible variability due to the specification that all boxes contain the core convective activity. The SCM simulations of the third storm observed during the Cirrus Regional Study of Tropical Anvils and Cirrus Layers-Florida Area Cirrus Experiment (CRYSTAL-FACE) show slightly more variability with a maximum deviation from the ensemble-mean vertically integrated mass flux of $12 \%$. This difference is likely because the STERAO and EULINOX CRM simulations employed uniform initial conditions, whereas the CRYSTAL-FACE simulation used nonuniform initial conditions derived from NCEP Eta model fields. CRM mass fluxes calculated for differing box locations showed variations of $4 \%$ or less in the CRYSTAL-FACE case.

In all three storms the choice of box location had little impact on simulated trace gas profiles. In the EULINOX case, SCM simulations show little variability in $\mathrm{CO}_{2}$ mixing ratios with the maximum spread among ensemble members, $0.5 \mathrm{ppmv}$, near the top of the boundary layer. Variations among $\mathrm{CRM}$ averaged $\mathrm{CO}_{2}$ mixing ratios were also small, maximizing at $0.8 \mathrm{ppmv}$ near the top of the cloud. Results from simulations of the STERAO and CRYSTAL-FACE storms also indicate that the selection of box location has little impact on trace gas profiles. In STERAO and CRYSTALFACE simulations of $\mathrm{CO}$, the maximum spread among ensemble members was found at anvil levels and ranged from 5 to $6 \mathrm{ppbv}$ in the CRM compared to approximately 7 ppbv in the SCM simulations. The maximum spread among CRYSTAL-FACE $\mathrm{CO}_{2}$ profiles was 0.3 in the CRM and 0.1 in the SCM. Since both convective mass flux and trace gas profiles show little sensitivity to the choice of averaging box location, the comparisons presented in sections 3 and 4 are for a single box location rather than the 10-member ensemble.

\section{Case studies}

\section{a. The 21 July 1998 EULINOX storms}

The EULINOX field campaign (Höller and Schumann 2000; Huntrieser et al. 2002) was conducted in central Europe during June and July 1998 with the goal of better understanding convective transport of trace gases and lightning $\mathrm{NO}_{x}$ production. During the project, airborne measurements of chemical species and meteorological properties were collected by the Deutsches Zentrum für Luft- und Raumfahrt (DLR) Falcon and the Do228 research aircraft. The Do228 flew primarily within the boundary layer and lower troposphere below $4 \mathrm{~km}$, whereas the Falcon investigated the upper troposphere and performed a number of anvil penetrations through monitored thunderstorms. Both radar and satellite observations were used to monitor the development of thunderstorms in the region. On the evening of 21 July 1998, the evolution of a severe thunderstorm west of Munich, Germany, was observed as part of the EULINOX campaign and is documented in Höller et al. (2000). The storm began as a single cell at approximately 1600 UTC and, after an initial period of intensification, the storm split into two distinct cells observed on radar at 1652 UTC. The northernmost cell became multicellular in structure and was observed to decay soon after the cell-splitting event, while the southern cell intensified and developed supercell characteristics, including a hook echo.

The GCE and CSCTM simulations of the July 21 EULINOX storm are fully described in Ott et al. (2007). The 3-h GCE simulation was successful in reproducing a number of observed storm features. Convection was initiated with a single warm thermal perturbation, and a single cell developed 20 min after the simulations had begun. At $70 \mathrm{~min}$, the cell splitting observed on radar occurred in the simulation. Subsequently, the southern cell developed a hook echo visible on plots of simulated radar reflectivity, while the northern cell evolved into a multicellular storm. Simulated cloud top heights were typically $14 \mathrm{~km}$, which compared favorably with observations (Höller et al. 2000) and a MM5 simulation of the same storm presented by Fehr et al. (2004). The GCE simulation was also able to reasonably reproduce vertical velocities calculated from an analysis of dualDoppler radar observations of the southern storm. Höller et al. reconstructed the $3 \mathrm{D}$ wind field in the southern cell at 1657 UTC, shortly after the cell-splitting event, and found a maximum updraft speed of $24 \mathrm{~m} \mathrm{~s}^{-1}$ and maximum downdraft speed of $9 \mathrm{~m} \mathrm{~s}^{-1}$. At the corresponding time in the GCE simulation ( $80 \mathrm{~min})$, the maximum updraft speed was $34 \mathrm{~m} \mathrm{~s}^{-1}$ and the strongest downdraft was $7 \mathrm{~m} \mathrm{~s}^{-1}$.

An initial condition profile of $\mathrm{CO}_{2}$ was constructed using data from the Falcon ascent and a value of 355 ppbv above the tropopause from Strahan et al. (1998). Initial conditions of $\mathrm{O}_{3}$ were produced by using data from the Falcon ascent, the Do228 aircraft that characterized the chemical composition of the boundary 
layer, and a climatological average ozone profile for the latitude of Munich at altitudes above $9 \mathrm{~km}$. The model did an excellent job of predicting mean in-cloud values of $\mathrm{CO}_{2}$ and $\mathrm{O}_{3}$ at $9 \mathrm{~km}$, though the range of observed $\mathrm{O}_{3}$ mixing ratios was larger than simulated. Probability distribution functions of simulated and observed $\mathrm{CO}_{2}$ demonstrated that the model was able to reasonably reproduce the range of observed in-cloud $\mathrm{CO}_{2}$ mixing ratios. The $\mathrm{O}_{3}$ pdfs suggested that the model was not able to reproduce the full range of values observed, consistent with findings at $9 \mathrm{~km}$. The discrepancy was attributed to the lack of observations above $9 \mathrm{~km}$ to well define the vertical gradients near the tropopause in the initial condition profiles. Because the simulation closely reproduced mean observed in-cloud mixing ratios at $9 \mathrm{~km}$ and the range of in-cloud $\mathrm{CO}_{2}$ mixing ratios, Ott et al. (2007) concluded that the simulation reasonably represented convective transport of trace gases.

$\mathrm{Xu}(1995)$ used the horizontal distributions of maximum cloud draft strength below the melting level and precipitation rate as criteria to partition a CRM domain into convective, stratiform, and cloud-free regions. Updraft convective mass flux was calculated by considering upward vertical motion in convective grid cells classified as saturated by the sum of cloud ice and water mixing ratios. The $\mathrm{Xu}$ methods were used to define convective regions in the CRM domain and to calculate the updraft convective mass flux in all three CRM simulations. The SCM was run for $3 \mathrm{~h}$ using initial condition and advective tendency profiles derived from the CRM output. Convective mass flux was averaged over $150 \mathrm{~min}$ of the SCM and CRM simulations, neglecting the first $30 \mathrm{~min}$, which are considered to be spinup. A comparison of the time-averaged updraft convective mass fluxes (Fig. 1a) shows that the SCM generates considerably less flux than the CRM. Convection is shallower in the SCM than in the CRM with convection in the SCM extending only to the tropopause height.

Out-of-cloud aircraft observations were used to estimate the state of the atmosphere prior to convection, and in-cloud observations were used to ensure that the CRM simulation reasonably represented convective transport. Owing to differences in scale, these observations are not intended for direct comparison with the model profiles but are presented in Fig. $1 \mathrm{~b}$ to provide information about the conditions used to construct the initial $\mathrm{CO}_{2}$ profile and evaluate the CRM performance. Averaging CRM results over a $150 \mathrm{~km} \times 150 \mathrm{~km}$ area yields a $\mathrm{CO}_{2}$ profile, verified with available observations, that is directly comparable to the SCM results.

The initial condition profile of $\mathrm{CO}_{2}$ (Fig. 1b) shows the maximum $\mathrm{CO}_{2}$ mixing ratios near the top of the boundary layer with lower mixing ratios below. Pollution from nearby Munich is likely responsible for enhancing $\mathrm{CO}_{2}$ mixing ratios throughout the boundary layer; however, photosynthesis results in some $\mathrm{CO}_{2}$ depletion near the surface. Despite a significant difference in $\mathrm{CO}_{2}$ mixing ratios in the boundary layer (from 367 to $372 \mathrm{ppmv}$ ) and the free troposphere (from 363 to 365 ppmv), profiles of $\mathrm{CO}_{2}$ mixing ratios calculated by both the CRM and SCM at the end of the 3-h simulations show little change from the initial condition profile (Fig. 1b). In the SCM, the lack of noticeable change in the $\mathrm{CO}_{2}$ profile following convection is due to the relatively weak convective mass flux, though most of the air is being entrained into the storm near the altitude of peak $\mathrm{CO}_{2}$ mixing ratios. In contrast, because the CRM entrains mass over a deeper layer from 1 to $3 \mathrm{~km}$, much of the air entering the storm has lower mixing ratios, reflecting the conditions above $1.5 \mathrm{~km}$. When averaged over a large area of the CRM domain, little increase in upper tropospheric mixing ratios is seen even though a wide range of mixing ratios are present in the $150 \mathrm{~km} \times$ $150 \mathrm{~km}$ area.

\section{b. The 10 July 1996 STERAO storm}

The STERAO-A (Dye et al. 2000; Stenchikov et al. 2005) field campaign was conducted in June and July 1996 and included two research aircraft. The NOAA WP-3D flew below $8 \mathrm{~km}$ to characterize the chemical environment in which storms developed, while the University of North Dakota Citation sampled the meteorological and chemical properties of thunderstorm anvils. On 10 July 1996, at approximately 2100 UTC, a multicellular thunderstorm organized in a northwestsoutheast line that developed near the WyomingNebraska border. The storm anvil was investigated by the Citation aircraft from 2237 to 0105 UTC, including a spiraling ascent in the anvil from 0024 to 0050 UTC. After 0115 UTC, the storm transitioned to a unicellular structure and displayed supercell characteristics (Dye et al. 2000).

The July 10 STERAO storm has been the subject of several modeling studies (e.g., Skamarock et al. 2000; 2003; Barth et al. 2007a) and also serves as the basis of a cloud-scale model intercomparison by Barth et al. (2007b). The storm was simulated by eight different CRMs, including the GCE and CSCTM, using identical initial conditions and the results were compared with radar and in-cloud aircraft observations. Storm intensity was evaluated by comparing the magnitude and height of simulated peak updraft velocity with observations throughout the 3-h simulation. Peak updraft velocities derived from radar observations ranged from 24 to $38 \mathrm{~m} \mathrm{~s}^{-1}$. The GCE produced updrafts within this range 

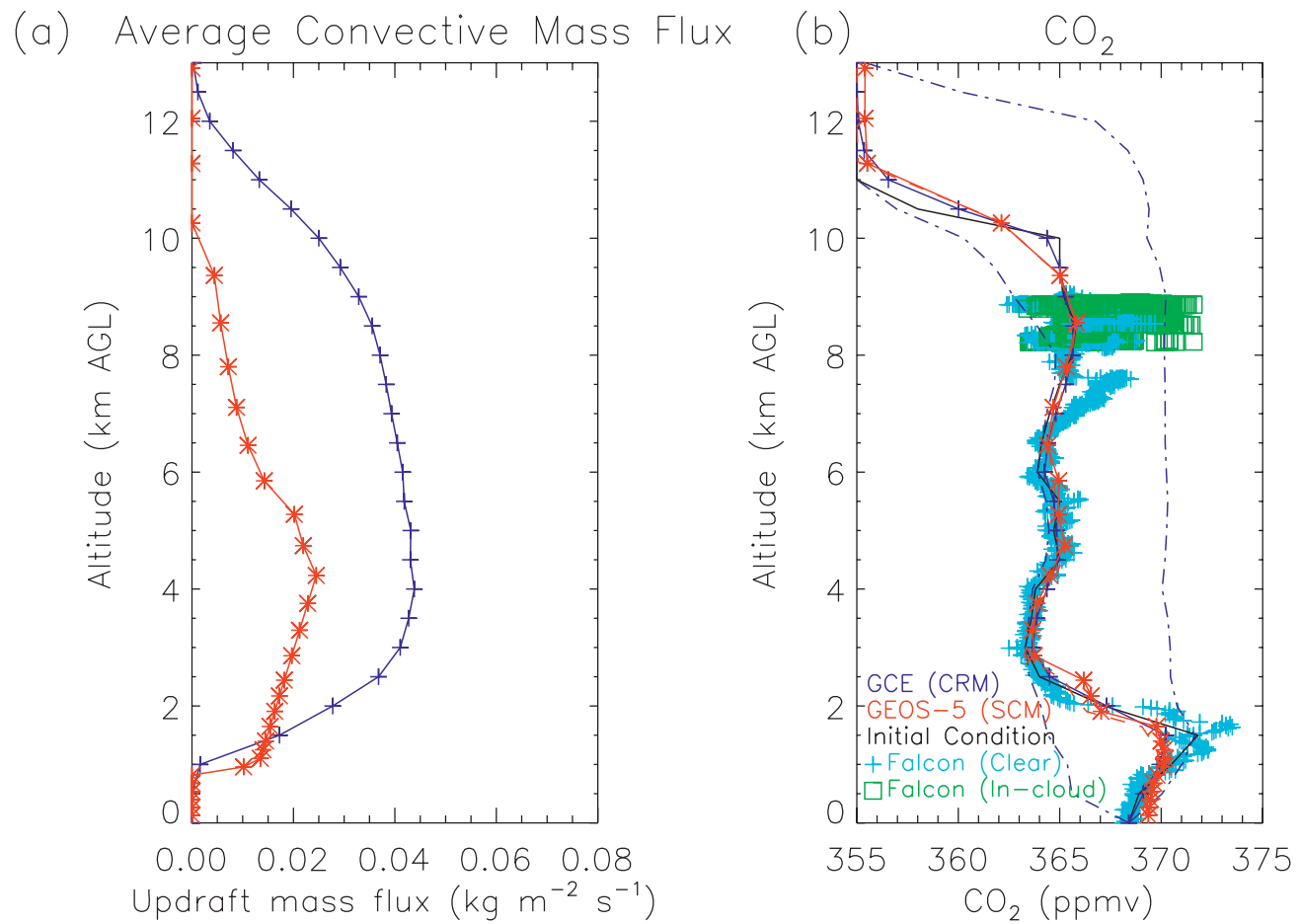

FIG. 1. (a) Convective mass flux from CRM (blue) and SCM (red) simulations of the 21 Jul EULINOX storm, averaged over $150 \mathrm{~min}$; (b) $\mathrm{CO}_{2}$ mixing ratios at the end of the 3-h CRM and SCM simulations compared with $\mathrm{CO}_{2}$ observations from the Falcon aircraft. Solid (dashed) red line shows $\mathrm{SCM} \mathrm{CO}_{2}$ calculated with (without) advective tendencies derived from CRM output, and the solid blue line indicates CRM results averaged over a $150 \mathrm{~km} \times 150 \mathrm{~km}$ region; the dashed-dotted blue lines show the maximum and minimum values within the averaging area. Plus signs (squares) represent observations from the Falcon aircraft taken outside (inside) the cloud.

from 60 min until the end of the simulation. The altitude of the maximum updraft was observed to range from 5.5 to $10 \mathrm{~km}$ MSL, and the GCE simulation calculated the height of the peak updraft within this range from 20 to $160 \mathrm{~min}$. The storm structure was examined by comparing horizontal and vertical cross sections of simulated and observed radar reflectivity. Anvil size was found to vary widely among the CRMs involved in the intercomparison due to differences in cloud microphysical treatments (Barth et al. 2007b). The GCE anvil was narrower than the observed anvil at its widest point but was longer because the simulation did not transition from a three-celled to a two-celled storm. Vertical cross sections showed that none of the CRMs were able to capture this transition. All CRMs, including the GCE, produced anvils that were higher in radar reflectivity and less extensive than observed. Additionally, the GCE simulation produced precipitation top heights at 60 min of $13 \mathrm{~km}$ MSL that were shallower than the 14$16.5 \mathrm{~km}$ MSL observed. Although not considered in the Barth et al. analysis, precipitation top heights from 90 to $180 \mathrm{~min}$ in the GCE simulation were $16 \mathrm{~km}$ MSL. The intercomparison concluded that the GCE, along with the other models, reasonably simulated the major storm features and was suitable for tracer transport calculations.

Initial condition profiles of $\mathrm{CO}$ and $\mathrm{O}_{3}$ were constructed using out-of-cloud aircraft data from the Citation as well as observations collected by the WP3D aircraft below $6 \mathrm{~km}$ in the region in which the storm developed (Skamarock et al. 2000). A comparison of aircraft observations from two cross-anvil transects and simulated $\mathrm{CO}$ and $\mathrm{O}_{3}$ mixing ratios was also included in the intercomparison presented by Barth et al. (2007b). The first transect occurred $10 \mathrm{~km}$ downwind of the southeasternmost convective core at a time corresponding to $60 \mathrm{~min}$ in the simulations and an elevation of $11.6 \mathrm{~km}$ MSL. The second transect was performed 50 $\mathrm{km}$ downwind of the same core 30 min later at $11.2 \mathrm{~km}$ MSL. The CSCTM underestimated the degree of enhancement in anvil CO observed during the first transect but performed better in the second comparison with a small overestimation of $\mathrm{CO}$ in some regions of the anvil. Similarly, the degree of $\mathrm{O}_{3}$ depletion in the first transect comparison of CSCTM output was less than observed, whereas the model performed well in the 

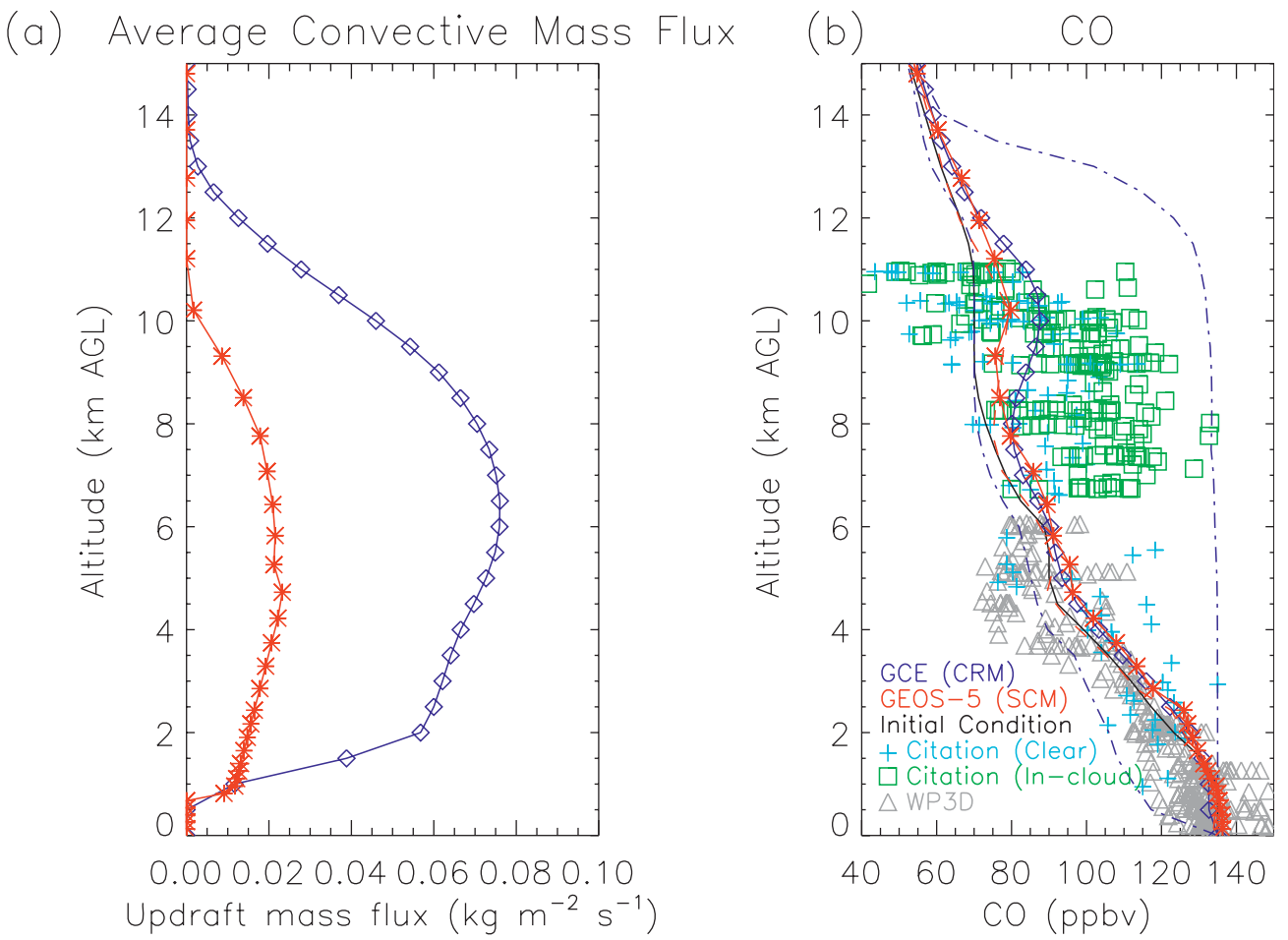

FIG. 2. As in Fig. 1 but (a) for the 10 Jul STERAO storm with (b) simulated CO mixing ratios compared to observations from the Citation and WP3D aircraft.

second comparison. Barth et al. (2007a) demonstrated that these results are sensitive to the selected location of the transects in the model domain, but despite this sensitivity, all models included in the intercomparison, including the CSCTM driven by the GCE, predicted values within $10 \%-15 \%$ of observed anvil $\mathrm{CO}$ and $\mathrm{O}_{3}$ mixing ratios (Barth et al. 2007b).

As in the 21 July EULINOX storm, the 3-h SCM simulation of the 10 July STERAO storm produced significantly less convective mass flux (Fig. 2a). The entrainment of air into the storm occurred in a shallower layer than in the CRM simulation and detrainment in the SCM convection occurred lower than in the CRM. The average CO profile calculated from CRM output at the end of the simulation shows a maximum enhancement of approximately $20 \mathrm{ppbv}$ in $\mathrm{CO}$ mixing ratios in the upper troposphere following convection (Fig. 2b), while the SCM profile shows a smaller increase at these altitudes. An SCM simulation that omitted advective tendencies suggests that most of the increase in $\mathrm{CO}$ above $11 \mathrm{~km}$ is due to horizontal advection.

\section{c. The 3 July 2002 CRYSTAL-FACE storm}

The CRYSTAL-FACE (Ridley et al. 2004; Lopez et al. 2006) field campaign was conducted in July 2002 over southern Florida. Six research aircraft were involved in the project, including the NASA WB-57, which measured microphysical, chemical, and meteorological properties of tropical cirrus anvils in the vicinity of the tropopause, and the Twin Otter, which sampled the chemical environment below $4 \mathrm{~km}$. A variety of observations, including radar, lidar, and rawinsonde, were provided by land-based stations.

On 3 July 2002, convection developed along the west coast of Florida at approximately 1600 UTC. At 1700 UTC, convective cells began to develop in the middle of the Florida peninsula and along a sea breeze front on the east coast. The area in and above the anvils associated with convection along the southeast coast was sampled by the WB57 from 1800 to 1945 UTC. Figure 3 shows Next Generation Weather Radar (NEXRAD) observed radar reflectivity overlaid on a GOES-8 visible image at 1932 UTC, approximately $210 \mathrm{~min}$ after convection began along the west coast. From 1939 to 1945 UTC, the ER-2 aircraft made a west-to-east pass above the southern portion of the convective system. Images from the ER-2 Doppler cloud radar (EDOP) aboard the ER-2 show precipitation top heights of $13.5 \mathrm{~km}$.

The 3 July CRYSTAL-FACE storm was simulated by the NASA Goddard version of the MM5 with a horizontal resolution of $2 \mathrm{~km}$ and vertical resolution of 0.5 


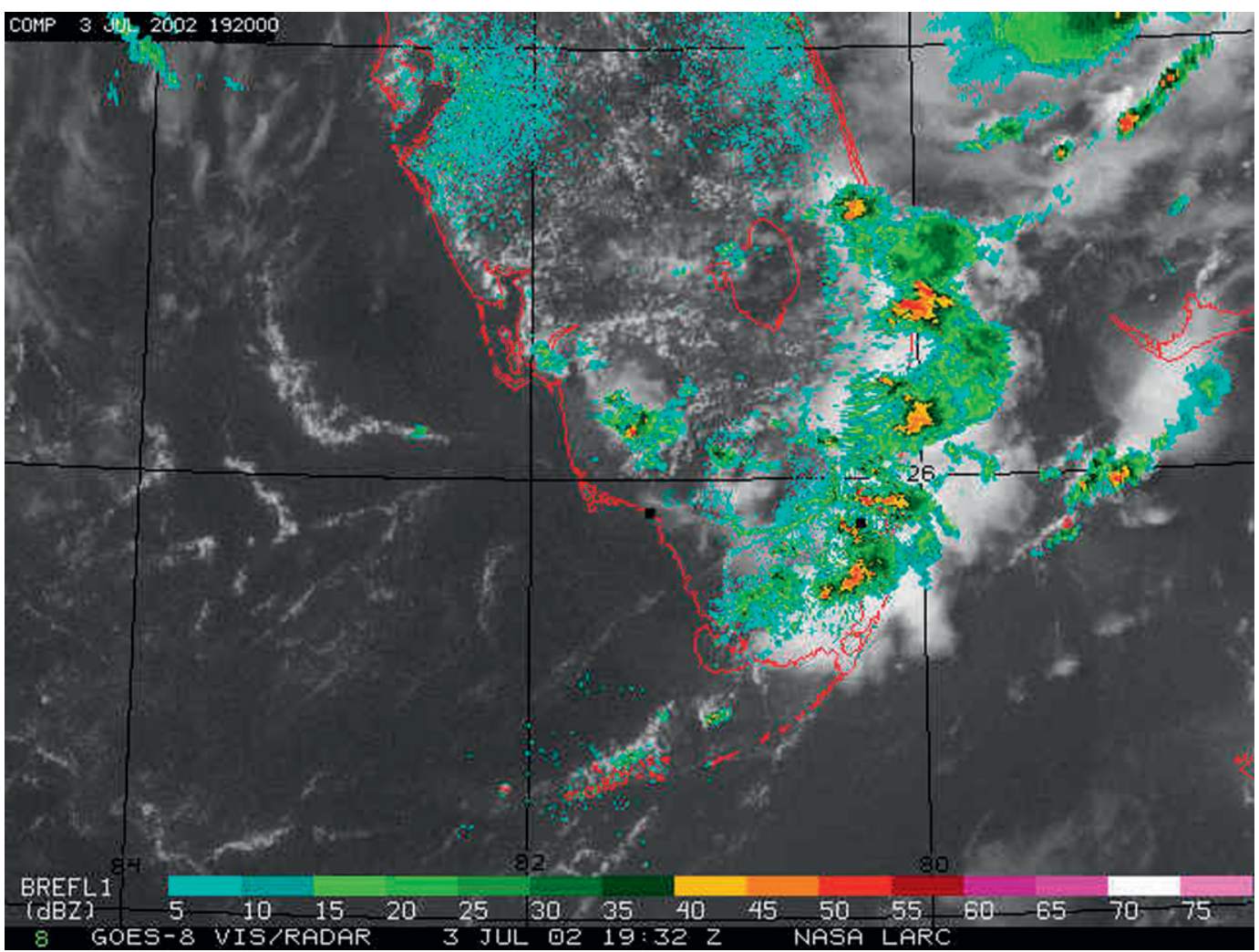

FIG. 3. NEXRAD radar reflectivity (dBZ) overlaid on a GOES-8 visible satellite image at 1930 UTC 3 Jul 2002. (Figure used with permission of L. Nguyen, NASA Langley Research Center.)

$\mathrm{km}$. Fields from the NCEP Eta model at 0000 UTC were used to initialize the model domain and boundary conditions derived from the Eta fields were updated at 3-h intervals. Because the simulation from 0000 to 1800 UTC was considered spinup, only the MM5 output from 1800 to 2400 UTC was used in comparisons with radar observations and tracer transport calculations.

The MM5 simulation captured many of the observed features of the 3 July CRYSTAL-FACE storm. Simulated convective cells are evident along the west coast of Florida at 1800 UTC, while observed convection began along the west coast at 1600 UTC. In the simulation, these convective cells move eastward across the Florida peninsula and reach the east coast at approximately 2230 UTC (Fig. 4). Observations show cells originating in the middle of the peninsula and along the east coast rather than propagating from the west coast as in the simulation. The simulated storms pass from the west to east coast in approximately $4.5 \mathrm{~h}$, while approximately $3.5 \mathrm{~h}$ elapsed between the beginning of the observed storms and the mature phase of the storms along the east coast. The size of the simulated convective system compares well with the observations at 1930 UTC (Fig. 3). The observed storm system extends from south
Florida at approximately $25.3^{\circ} \mathrm{N}$ to just north of Lake Okeechobee at $27.3^{\circ} \mathrm{N}$ along the east coast. In the simulation, convection extends over a similar range of latitudes. A cross section through the southern portion of the simulated storm at 2240 UTC shows that precipitation top heights were $14.5 \mathrm{~km}$-slightly higher than the observed precipitation top height of 13.5 between 1939 and 1945 UTC. The simulated storm anvil reaches its widest point at $10 \mathrm{~km}$, which agrees with EDOP observations. At this level the simulated anvil width was approximately $70 \mathrm{~km}$, compared to a 60 -km-wide observed anvil. Maximum vertical velocity associated with the simulated storm was $33 \mathrm{~m} \mathrm{~s}^{-1}$. Although no observations of vertical velocity were available during CRYSTALFACE, Lopez et al. (2006) reported peak updraft speeds in simulations of three thunderstorms observed during CRYSTAL-FACE of 30,40 , and $60 \mathrm{~m} \mathrm{~s}^{-1}$.

The period of greatest interest during the observed storm is from 1600 to 2000 UTC, when cells developing across the Florida peninsula were sampled by the WB57 aircraft. In the MM5 simulation, convection is located along the east coast at 2300 UTC. As a result, tracer transport was calculated using the MM5 fields from 1900 to 2300 UTC. Initial condition profiles of $\mathrm{CO}$ and $\mathrm{CO}_{2}$ 

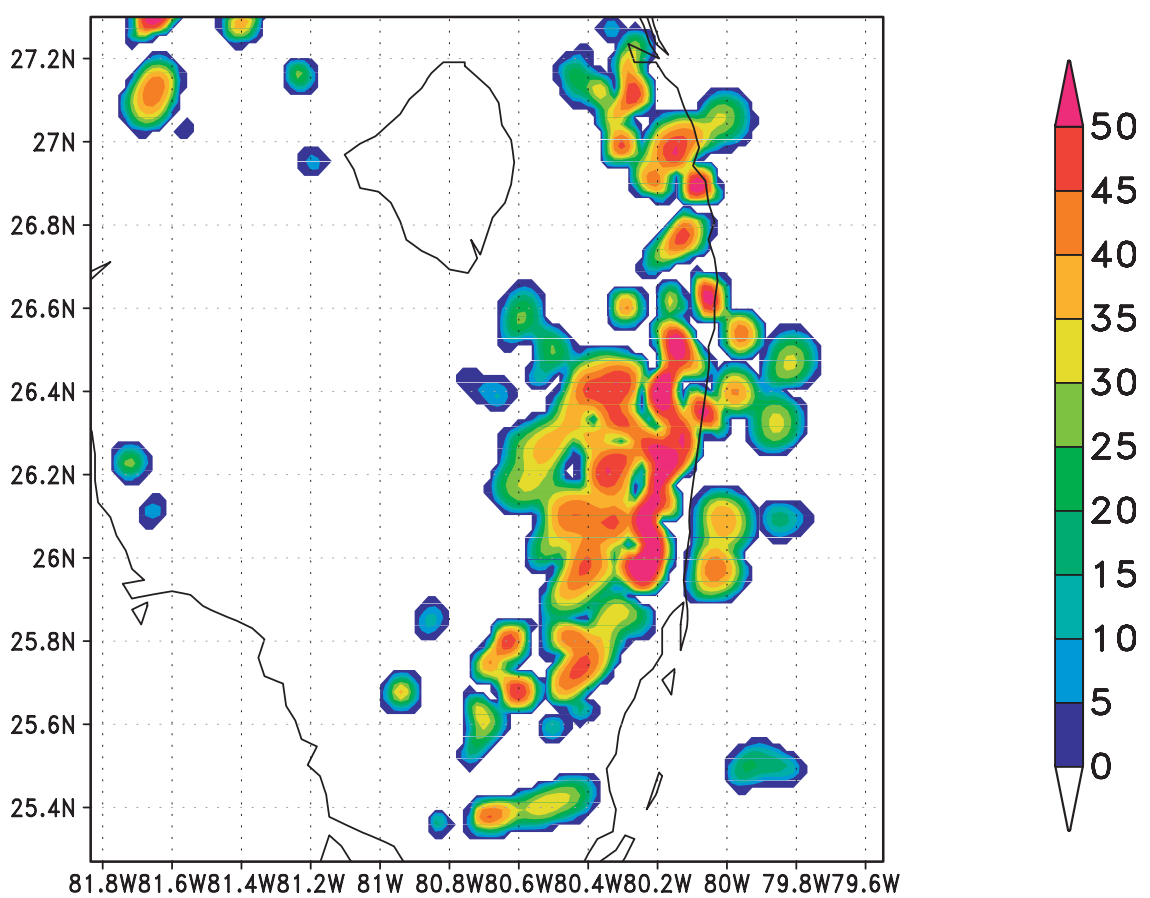

FIG. 4. Radar reflectivity at $0.5 \mathrm{~km}$ calculated from MM5 simulated hydrometeor fields at 2230 UTC during the 3 Jul CRYSTAL-FACE storm.

were constructed using the mean values of out-of-cloud data collected during the ascent and descent of the WB57 and portions of the flight in clear air. Because WB57 observations of $\mathrm{CO}$ were not available below 8 $\mathrm{km}$ and Twin Otter CO measurements were not available on 3 July, sensitivity tests with different assumptions of low-level $\mathrm{CO}$ were performed. The first profile assumed a boundary layer value of 160 ppbv, approximately the project-mean Twin Otter profile, and was linearly interpolated between the top of the boundary layer and $8 \mathrm{~km}$ following Lopez et al. The remaining profiles assumed boundary layer values of 140 and 180 ppbv and were also linearly interpolated between the assumed boundary layer value and $8 \mathrm{~km}$, producing three profiles with different values at low levels but identical values at anvil levels. In the profile with an assumed boundary layer mixing ratio of $180 \mathrm{ppbv}$, the maximum convective enhancement of $\mathrm{CO}$ averaged over all in-cloud grid cells after $4 \mathrm{~h}$ of simulation was $29 \mathrm{ppbv}$ at $11 \mathrm{~km}$. In the simulations assuming lower boundary layer values of 160 and $140 \mathrm{ppbv}$, the enhancements in $\mathrm{CO}$ at $11 \mathrm{~km}$ were 22 and 14 ppbv, respectively. Because the storms occurred near the heavily populated Miami-Ft. Lauderdale area, the remaining calculations presented assume the profile with a boundary layer value of 180 ppbv. This value is approximately 20 ppbv higher than the mean of measurements from the Twin Otter flights, which were primarily conducted over ocean and along Florida's less populous west coast.

Aircraft observations collected during CRYSTALFACE present a unique challenge for studies interested in convective transport of trace gases [see full discussion in Lopez et al. (2006)]. Because the project was designed to study the properties of cirrus anvils, flights were typically performed in thin cirrus or in the upper portion of thicker anvils. As a result, measured in-cloud mixing ratios of trace gases typically showed a smaller degree of enhancement over background conditions than would be expected had the updraft cores or thicker regions of the anvil been sampled as in other field campaigns. To compare CRM output with observations of CO in thin cirrus, Lopez et al. sampled model output with ice water contents between 1 and 50 ppmv. We use the same method here for the 3 July CRYSTAL-FACE storm and extend this method to examine $\mathrm{CO}_{2}$ mixing ratios (Fig. 5). In-cloud aircraft observations taken between 1800 and 1945 UTC are compared with CRM output sampled from 2000 to 2245 UTC owing to the differences in timing between the simulation and observations discussed above. Between 12.5 and $13.5 \mathrm{~km}$, the simulation underestimates $\mathrm{CO}$ when either the whole cloud (all grid cells with ice water content greater than 1 ppmv) or only thin cloud (only grid cells with ice water content between 1 and 50 ppmv) are considered. This is likely due to uncertainty in the definition of the 

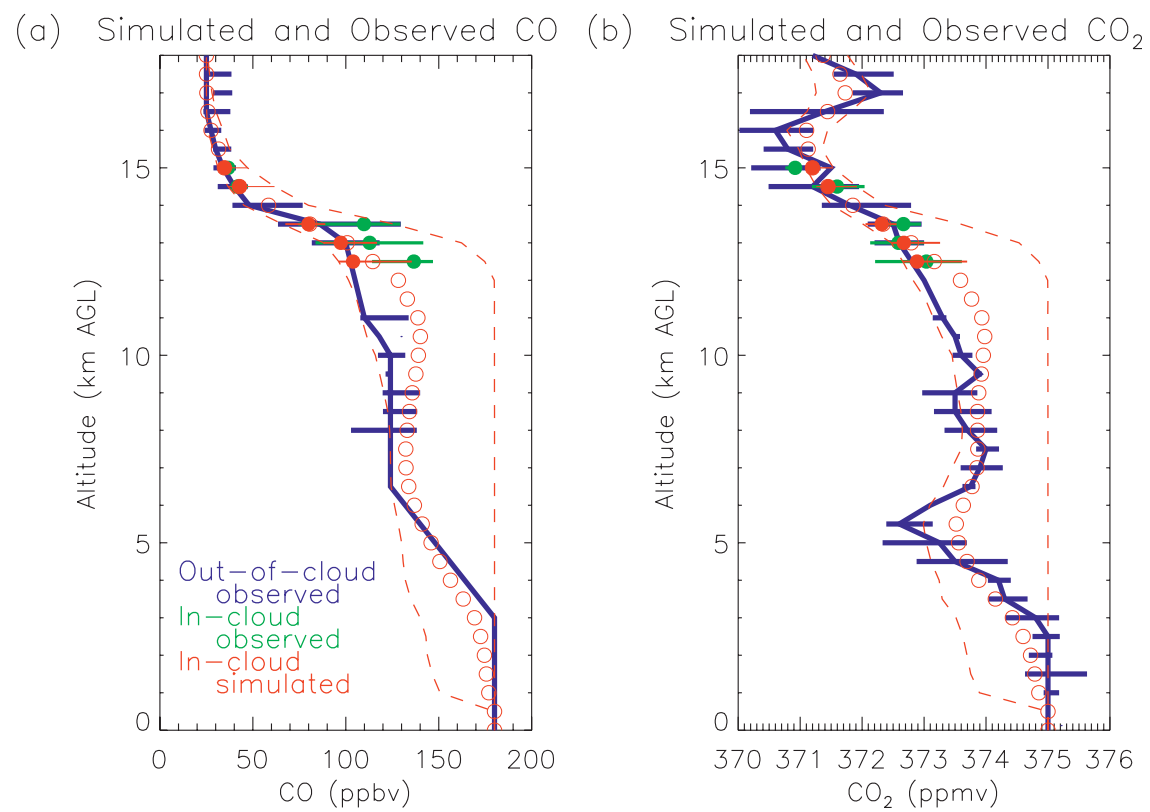

FIG. 5. Profiles of simulated and observed (a) $\mathrm{CO}$ and (b) $\mathrm{CO}_{2}$ in the 3 Jul CRYSTALFACE storm. The initial condition profiles (blue) are derived from mean out-of-cloud aircraft observations with the range of measurements indicated by the bars. Open red circles show the mean simulated in-cloud (all grid cells with ice water content greater than $1 \mathrm{ppmv}$ ) tracer mixing ratio; the dashed line indicates the range of in-cloud values at each model level. Solid red circles represent the mean in-cloud mixing ratio in thin cirrus (only grid cells with ice water content between 1 and $50 \mathrm{ppmv}$ ); red bars indicate the range of in-cloud values using this sampling method. Green dots and bars indicate the mean in-cloud observed mixing ratio; green bars indicate the range of in-cloud aircraft observations.

initial condition $\mathrm{CO}$ profiles because a similar underestimation is not present in the $\mathrm{CO}_{2}$ comparison. It should also be noted that out-of-cloud observations of $\mathrm{CO}$ at 13 and $13.5 \mathrm{~km}$ exhibit a high degree of variability. A sensitivity test in which the initial condition $\mathrm{CO}$ profile was constructed using the mean plus one standard deviation produced an improved comparison with measurements taken in-cloud. Simulated and observed $\mathrm{CO}_{2}$ mixing ratios compare well at all altitudes sampled, though both show little difference from background conditions. Because $\mathrm{CO}_{2}$ observations were available from the surface to the tropopause to guide the construction of the initial $\mathrm{CO}_{2}$ profile, the $\mathrm{CO}_{2}$ comparisons provide greater insight into the success of the simulated convective transport and indicate that transport in the simulation is reasonable.

The SCM was run for $4 \mathrm{~h}$ with initial conditions and forcing derived from the MM5 fields from 1900 to 2300 UTC. Convective mass flux was averaged over the final 210 min of both the CRM and SCM simulations. As in the two midlatitude storms presented in sections $3 \mathrm{a}$ and $3 \mathrm{~b}$, the SCM simulation produced significantly less convective mass flux than the CRM simulation (Fig. 6a). Both SCM and CRM simulations indicate a lower cloud base in the CRYSTAL-FACE storm than in the STERAO and EULINOX storms, likely due to greater moisture in the boundary layer over Florida. In the SCM simulation of the 3 July CRYSTAL-FACE storm, most air is entrained into the storm at approximately 0.5 $\mathrm{km}$, whereas in the CRM simulation air is entrained from near the surface to $2 \mathrm{~km}$. Mixing ratios of $\mathrm{CO}$ and $\mathrm{CO}_{2}$ are enhanced over the background values from 7 to $13 \mathrm{~km}$, the region in which air is detrained from the storm in the CRM mass flux profile.

Generally, the CRM profiles of $\mathrm{CO}$ and $\mathrm{CO}_{2}$ compare well with the available observations at anvil levels. The CRM tracer profiles shown are area averages at the end of the 300-min simulation, whereas the aircraft observations were taken over the course of the WB57 flight, which lasted from 1600 to 2130 UTC. The region of the peninsula in which convection was active was sampled from approximately 1650 to 1950 after which the plane sampled an area off the west coast of Florida before landing in Key West. Apparent differences in the simulated trace gas profiles and observations may be the result of these spatial and temporal differences. Loewenstein et al. (2003) found that the high CO mixing ratios observed at approximately 7 and $11 \mathrm{~km}$ on 3 July 
(a) Average Convective Mass Flux (b)

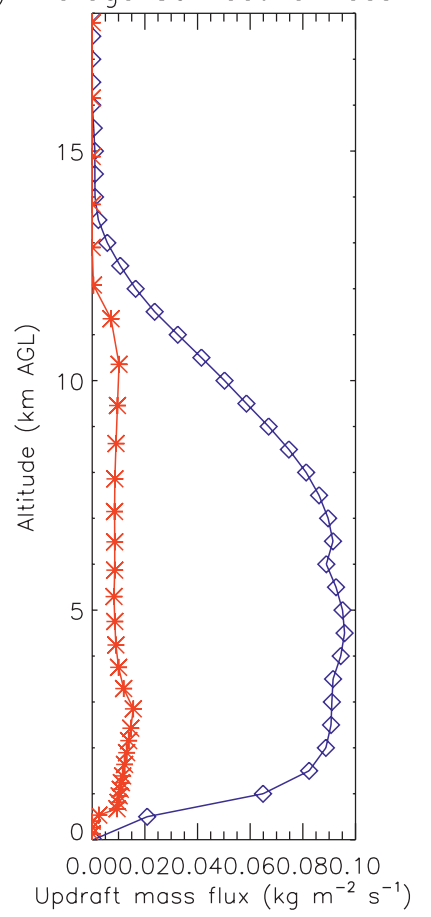

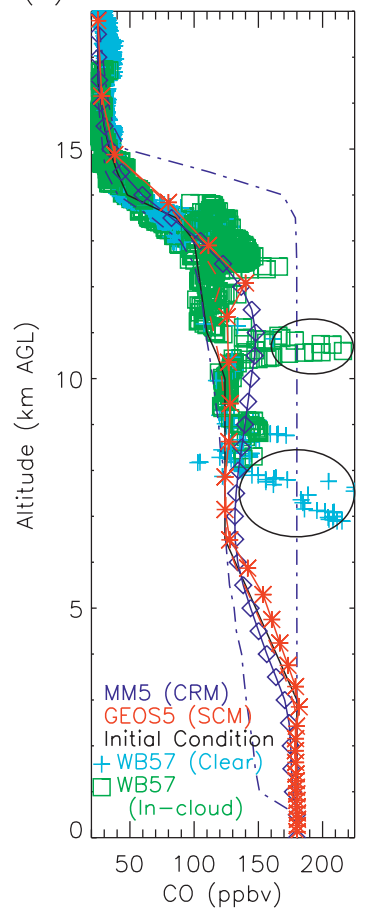

(c)

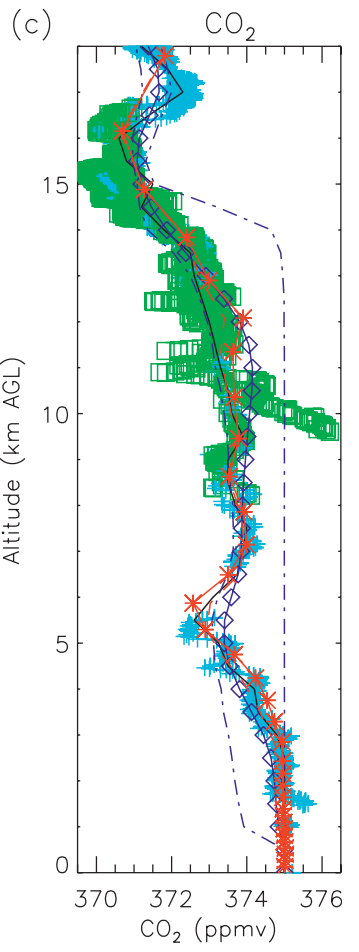

FIG. 6. (a) Convective mass flux from the CRM (blue) and SCM (red) simulations of the 3 Jul CRYSTALFACE storm averaged over $210 \mathrm{~min}$; (b) $\mathrm{CO}$ and (c) $\mathrm{CO}_{2}$ mixing ratios at the end of the 4-h simulations compared with observations from the WB57 aircraft. Solid (dashed) red line shows SCM CO and $\mathrm{CO}_{2}$ calculated with (without) advective tendencies derived from CRM output. The solid blue line indicates CRM results averaged over a $150 \mathrm{~km} \times 150 \mathrm{~km}$ region; the dashed-dotted blue lines show the maximum and minimum values within the averaging area. Plus signs (squares) represent aircraft observations from the WB57 taken outside (inside) of the cloud. Circled areas in (b) indicate measurements that may be influenced by biomass burning or outflow from a previous convective event.

may have resulted from biomass burning or convective outflow from a previous storm. Elevated $\mathrm{CO}_{2}$ mixing ratios at these levels likely have a similar origin. Because observations at these altitudes occurred only during the aircraft ascent and descent out of Key West, it was not possible to determine if these values represented conditions over the Florida peninsula where convection developed or a more localized plume. As a result, these values were not used in constructing initial condition profiles and are not expected to be reproduced by either the SCM or CRM simulations. Significantly weaker convective mass flux in the SCM simulation resulted in little convective transport of $\mathrm{CO}$ and $\mathrm{CO}_{2}$. Peaks seen in the SCM profiles of these species at $12 \mathrm{~km}$ are largely the result of the advective tendencies that were derived from the CRM simulation.

\section{Parameter sensitivity}

Comparisons of convective mass flux from the simulations of three storms showed that the convective mass flux produced by the SCM was substantially weaker than that from the CRMs. This results in less upward transport of trace gases from the boundary layer and can significantly affect mixing ratios in the mid and upper troposphere. To investigate the sensitivity of convective transport in the SCM to the values of parameters contained in the moist physics schemes, regional sensitivity analysis (RSA) (Hornberger and Spear 1981) was used. The implementation of this method follows closely that of Liu et al. (2004), who used a multiple criteria extension to RSA developed by Bastidas et al. (1999) to investigate parameter sensitivity in a coupled landatmosphere model.

A simpler one-at-a-time screening was used to reduce the parameter space prior to the more rigorous and computationally intensive RSA, as in Liu et al. (2004). The current implementation of moist physics in GEOS-5 includes a total of 56 parameters, 20 used in the RAS convective scheme and 36 in the prognostic cloud scheme. Feasible ranges of the 56 parameters were determined based on the functions of each parameter and a review of relevant literature. To determine the sensitivity of each parameter, the SCM was run for each of 
the three storms with a single parameter perturbed while all other parameters were held constant. Each parameter was perturbed at $10 \%$ intervals from the minimum to the maximum value of the feasible range. The 16 parameters whose perturbation resulted in a $1 \%$ or greater change in the time-averaged vertically integrated convective mass flux of any storm were considered in the subsequent RSA. A list of these parameters, their default values, and feasible ranges is provided in Table 1.

Unlike the one-at-a-time approach in which one parameter is varied while others remain fixed, RSA involves simultaneous variation of all parameters, which allows parameter interdependencies to be accounted for in the sensitivity analysis. A number of samples, or parameter sets, are selected at random from the designated feasible ranges and the SCM is run with each set. The RSA then requires some criteria to divide the samples into a behavioral class (containing those simulations which produce the most favorable results) and a nonbehavioral class (containing the remaining simulations in the sample) with the goal of identifying parameter sets that produce the most favorable outcomes. For the purpose of evaluating convective transport, time-averaged vertically integrated convective mass flux derived from the CRM simulations was used as a criteria because direct observations of convective mass flux are not possible. Samples are ranked based on their ability to reproduce the CRM mass flux and, following Bastidas et al. (1999) and Liu et al. (2004), an arbitrary rank threshold is used to partition samples into behavioral and nonbehavioral classes. Cumulative parameter distributions are computed for both classes, and the Kolmogorov-Smirnov (K-S) test is used to determine if these distributions are statistically different. If so, a parameter would be considered to be sensitive. As in Liu et al., the $\mathrm{K}-\mathrm{S}$ test is repeated using 200 bootstrapped samples and the $\mathrm{K}-\mathrm{S}$ test statistic used to indicate sensitivity is the median of the values obtained. The procedure is repeated with successively larger sample sizes until the number of sensitive parameters stabilizes.

The lower the value of the K-S probability for a parameter, the higher the sensitivity. Liu et al. considered all parameters with a $\mathrm{K}-\mathrm{S}$ probability less than 0.01 to be highly sensitive and all parameters with a probability greater than 0.05 to be insensitive. Parameters with probabilities between 0.01 and 0.05 were deemed somewhat sensitive for the purpose of identifying parameters to be included in calibration studies. In this study, we consider only parameters with a $\mathrm{K}-\mathrm{S}$ probability less than 0.01 to be sensitive. This criterion provided the greatest stability and was sufficient for the purpose of identifying the most important parameters with respect to convective transport.

To evaluate the sensitivity of the results to the choice of rank threshold used for partitioning samples into behavioral and nonbehavioral classes, several different rank values were tested. A rank of 20 was selected for these studies because it provided the greatest stability regardless of sample size in all cases. The results from the RSA of the three storms are presented in Fig. 7. In the case of the 21 July EULINOX storm, the number of sensitive parameters stabilized with a sample size of 12000 . The five parameters identified as sensitive with respect to convective mass flux were RASAL1 and RASAL2 (used to determine the relaxation time scale), ACRITFAC (a factor used to compute the critical value of the cloud work function that determines the initiation of convection), BASE_EVAP_FAC (used to determine the amount of rain evaporated into the environment), and AUTOC_CN (used in the calculation of the autoconversion of convective condensate). The number of sensitive parameters in the 10 July STERAO storm stabilized using a sample size of 18000 and identified six parameters as sensitive. In addition to the five sensitive parameters from the EULINOX simulations, the LAMBDA_FAC parameter (used to calculate the minimum entrainment rate) also displayed sensitivity in the 10 July STERAO storm. The RSA in the 3 July CRYSTAL-FACE storm stabilized at a sample size of 10 000. The MIN_DIAMETER parameter (used to calculate the maximum entrainment rate) was deemed to be sensitive in the CRYSTAL-FACE storm, along with the five parameters common to the STERAO and EULINOX analyses.

Comparing the distributions of parameters in the behavioral and nonbehavioral classes can also provide insight into which values produce the most favorable results. In the three cases analyzed, the use of default parameter settings resulted in much weaker convection in SCM simulations than in CRM simulations of the same storms. Members of the behavioral class of SCM simulations contained altered parameter settings that effectively increased the convective mass flux. Values of the parameters RASAL1 and RASAL2, which produce short relaxation time scales, yielded the best comparison with CRM simulated mass flux. Values of the BASE_EVAP_FAC close to the upper limit of 1 produced better comparisons with the CRM results than values near the lower limit of 0 . Large values of BASE_EVAP_FAC correspond to a higher degree of evaporation of falling precipitation, which increases moisture in the model domain and facilitates stronger and more sustained convection. Similarly, low values of the parameter AUTOC_CN produce better results by 
TABLE 1. Selected physics parameters varied in this study. Default values in the GEOS-5 SCM as well as minimum and maximum values used here are given. Parameters AUTOC_\{LS,CN $\}$ and QC_CRIT_\{LS,CN $\}$ are used in Sundquist-type expressions for autoconversion (Bacmeister et al. 2006). Entrainment rates $\left(\mathrm{m}^{-1}\right)$ in RAS are assumed to be related to an imagined cloud radius $R$ according to $M^{-1} d M / d z=0.2 / R$ as in Simpson and Wiggert (1969).

\begin{tabular}{|c|c|c|c|c|}
\hline & Default & Minimum & Maximum & Description \\
\hline \multicolumn{5}{|c|}{ RAS parameters } \\
\hline AUTOC_CN & $2.50 \times 10^{-3}$ & $1.00 \times 10^{-4}$ & $1.00 \times 10^{-2}$ & $\begin{array}{l}\text { Maximum autoconversion rate }\left(\mathrm{s}^{-1}\right) \text { for } \\
\text { convective condensate }\end{array}$ \\
\hline QC_CRIT_CN & $8.00 \times 10^{-4}$ & $1.00 \times 10^{-4}$ & $1.00 \times 10^{-2}$ & $\begin{array}{l}\text { Critical value }\left(\mathrm{g} \mathrm{g}^{-1}\right) \text { for autoconversion } \\
\text { of convective condensate }\end{array}$ \\
\hline RASAL1 & 1800 & 1800 & $1.00 \times 10^{5}$ & $\begin{array}{l}\text { Minimum convective relaxation time scale (s). } \\
\text { Used for shallow clouds (tops }<2 \mathrm{~km} \text { ) }\end{array}$ \\
\hline RASAL2 & $1.00 \times 10^{5}$ & 1800 & $1.00 \times 10^{5}$ & $\begin{array}{l}\text { Maximum convective relaxation time scale (s). } \\
\text { Used for deep clouds (tops } \sim 10 \mathrm{~km} \text { ) }\end{array}$ \\
\hline LAMBDA_FAC & 4 & 1 & 10 & $\begin{array}{l}\text { Ratio of maximum cloud diameter to subcloud } \\
\text { layer thickness. Controls minimum } \\
\text { entrainment rate }\end{array}$ \\
\hline MIN_DIAMETER & 200 & 100 & 300 & $\begin{array}{l}\text { Minimum cloud diameter }(\mathrm{m}) \text {. Determines } \\
\text { maximum entrainment rate via } \\
\text { Simpson relation }\end{array}$ \\
\hline ACRITFAC & 0.5 & 0.1 & 1 & Scaling factor for critical cloud work function \\
\hline \multicolumn{5}{|c|}{ Prognostic cloud parameters } \\
\hline CNV_BETA & 10 & 0.1 & 10 & $\begin{array}{l}\text { Scaling factor for area of convective } \\
\text { rain showers }\end{array}$ \\
\hline ANV_BETA & 4 & 0.1 & 10 & $\begin{array}{l}\text { Scaling factor for area of showers falling } \\
\text { from anvil clouds }\end{array}$ \\
\hline RH_CRIT & 0.95 & 0.95 & 1 & Critical relative humidity for cloud formation \\
\hline AUTOC_LS & $2.00 \times 10^{-3}$ & $1.00 \times 10^{-4}$ & $1.00 \times 10^{-2}$ & $\begin{array}{l}\text { Maximum autoconversion rate }\left(\mathrm{s}^{-1}\right) \text { for large } \\
\text { scale condensate }\end{array}$ \\
\hline QC_CRIT_LS & $8.00 \times 10^{-4}$ & $1.00 \times 10^{-4}$ & $1.00 \times 10^{-2}$ & $\begin{array}{l}\text { Critical value }\left(\mathrm{g} \mathrm{g}^{-1}\right) \text { for autoconversion } \\
\text { of large-scale condensate }\end{array}$ \\
\hline BASE_EVAP_FAC & 1 & 0 & 1 & $\begin{array}{l}\text { Fraction of estimated rain evaporation } \\
\text { actually applied }\end{array}$ \\
\hline ANV_ICEFALL & 1 & 0.1 & 1 & $\begin{array}{l}\text { Scaling parameter for sedimentation } \\
\text { velocity of cloud ice }\end{array}$ \\
\hline CNV_ENVF & 0.8 & 0.1 & 1 & $\begin{array}{l}\text { Fraction of precipitation assumed to fall } \\
\text { through environment }\end{array}$ \\
\hline ICE_RAMP & -40 & -60 & -20 & $\begin{array}{l}\text { Temperature }\left({ }^{\circ} \mathrm{C}\right) \text { below which newly formed } \\
\text { condensate is assumed to be pure ice }\end{array}$ \\
\hline
\end{tabular}

reducing the autoconversion of convective condensate and, consequently, precipitation. The critical value of the cloud work function, ACRITFAC, determines the threshold for the initiation of convective adjustment. Smaller values of ACRITFAC result in a greater number of plumes contributing to the net mass flux of the cloud ensemble, thereby increasing the convective mass flux. The sensitivity of the LAMBDA_FAC and MIN_DIAMETER parameters in individual storms indicates that the maximum and minimum values of the entrainment rate may also influence convective mass flux in certain conditions.

To further explore the impact of parameter settings on convection, vertical trace gas and convective mass flux profiles were averaged for all simulations in the behavioral class. In the 21 July EULINOX storm, the behavioral profile of time-averaged convective mass flux shows more entrainment than the CRM profile below $4 \mathrm{~km}$ (Fig. 8a). As in the control SCM run, the majority of air is entrained into the storm from a shallow layer approximately $1 \mathrm{~km}$ above the ground. The behavioral mass flux profile shows detrainment occurring from 4 to $10.5 \mathrm{~km}$, whereas the CRM profile decreases slightly from 4 to $8.5 \mathrm{~km}$ and then more rapidly above $8.5 \mathrm{~km}$. The largest difference between the behavioral and $\mathrm{CRM} \mathrm{CO}_{2}$ profiles is seen in the $1-2.5-\mathrm{km}$ region where $\mathrm{CO}_{2}$ is depleted in the behavioral simulations due to the stronger SCM mass flux (Fig. 8b). $\mathrm{CO}_{2}$ mixing ratios are slightly larger from 4 to $8 \mathrm{~km}$ in the behavioral profile than in the CRM profile because more high $\mathrm{CO}_{2}$ 


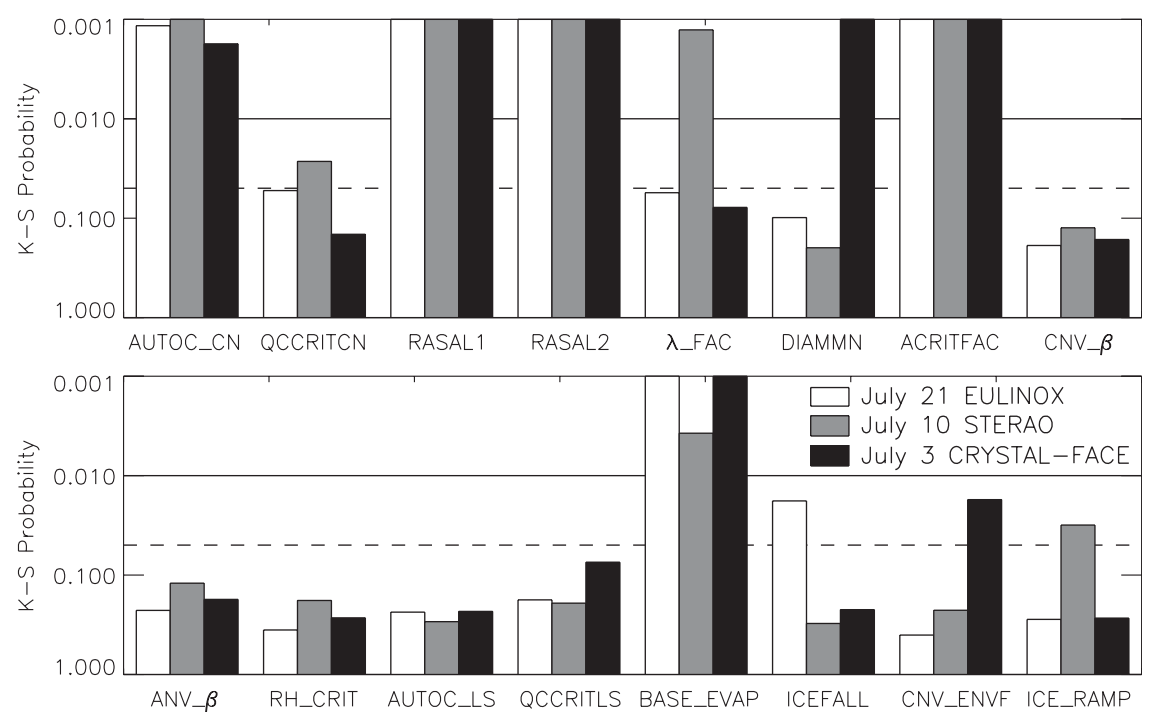

FIG. 7. Kolmogorov-Smirnov probabilities computed from RSA for 16 parameters listed in Table 1 for the EULINOX (white), STERAO (gray), and CRYSTAL-FACE (black) storms. Solid line indicates the threshold for determining sensitive parameters. Dashed line designates somewhat sensitive criteria from Liu et al. (2004).

air is transported upward from the boundary layer and detrained at these levels. In this storm, parameter settings that result in increased convective mass flux do not seem to improve the comparison between the CRM and $\mathrm{SCM} \mathrm{CO}_{2}$ profiles. This arises from the difference in entrainment and detrainment levels in the CRM and SCM simulations.

The mean behavioral profile of time averaged mass flux for the 10 July STERAO storm (Fig. 9a) is similar in shape to that of the 21 July EULINOX storm. Entrainment in the behavioral profile is greater than in the CRM simulation below $4 \mathrm{~km}$. Detrainment begins at approximately $4 \mathrm{~km}$ in the behavioral SCM profile and occurs more rapidly near the top of the cloud, from 8 to $11 \mathrm{~km}$. In contrast, the CRM simulation continues to entrain air into the storm up to $6.5 \mathrm{~km}$ and then detrains air up to 14 $\mathrm{km}$. In the CO profiles (Fig. 9b), the greater degree of low-level entrainment in the behavioral simulations results in an underestimation of the CRM CO mixing ratios from 1 to $4 \mathrm{~km}$. Nearly constant $\mathrm{CO}$ mixing ratios from 3.5 to $4.5 \mathrm{~km}$ in the behavioral profile mark the transition from entrainment to detrainment as seen in the mass flux profile. A similar feature is not noticeable in the default SCM profile because of the much weaker convective mass flux. From 7 to $9 \mathrm{~km}$, the behavioral simulations slightly overestimate $\mathrm{CO}$ mixing ratios with respect to the CRM due to the greater detrainment at these levels in the SCM simulations of the storm. From 9 to $11 \mathrm{~km}$, the behavioral CO profile compares well with the CRM profile because of the increase in convective mass flux resulting from parameter changes.
The mean behavioral profile of time averaged convective mass flux in the 3 July CRYSTAL-FACE storm shows that the SCM continues to underestimate mass flux relative to the CRM simulation even with altered parameter settings (Fig. 10a). However, the increase in mass flux resulting from changes in parameter values improves the representation of both $\mathrm{CO}$ and $\mathrm{CO}_{2}$ from 9 to $11.5 \mathrm{~km}$ because more air originating at low levels has been transported upward (Figs. 10b and 10c).

\section{Summary and conclusions}

Many evaluations of the meteorological aspects of convection parameterizations have been presented in the past, often comparing SCM results with CRM results, which are more easily validated against observations and can provide detailed information on cloud processes. This study extends that approach to examine the vertical distributions of trace gases and convective mass flux produced by a SCM during three convective events observed during field projects. Because cloud mass flux, the quantity used by CTMs and GCMs to calculate convective transport, cannot be observed, it is necessary to use CRMs as a proxy for observations. A comparison of radar observations and CRM output showed that the simulations were able to reproduce the dynamical evolution and structure of the observed storms. CRMs are also useful as a means of interpreting aircraft observations that represent both in- and outof-cloud chemical environments, which may differ substantially. Comparison of CRM results with in-cloud 

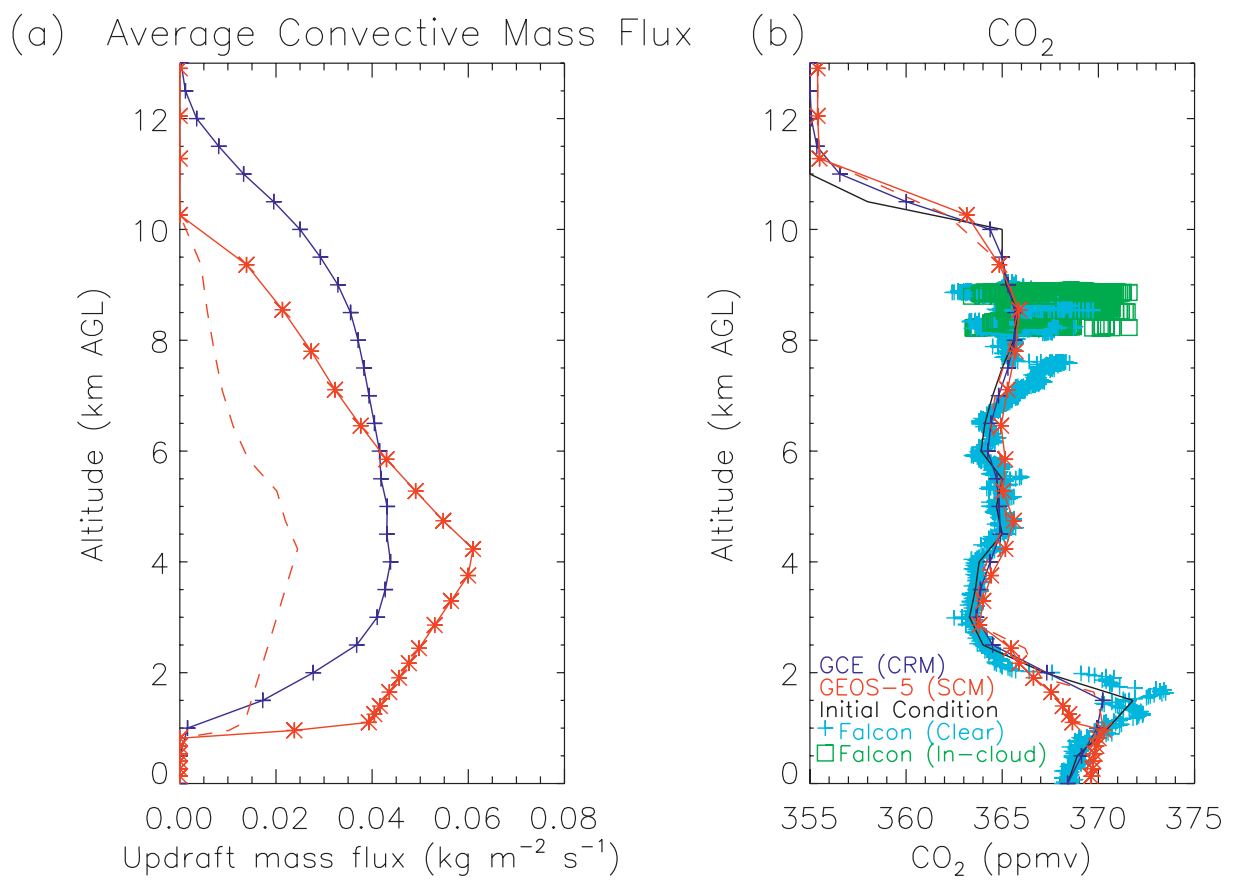

FIG. 8. Vertical profiles of (a) convective mass flux and (b) $\mathrm{CO}_{2}$ from CRM (blue) and SCM (red) simulations of the $21 \mathrm{Jul}$ EULINOX storm. Solid red lines represent the average over all simulations in the behavioral class while dashed red lines represent the control simulation assuming default parameter settings. Mass flux profiles are averaged over $150 \mathrm{~min} . \mathrm{CO}_{2}$ mixing ratios are calculated at the end of the 3-h simulations and compared with $\mathrm{CO}_{2}$ observations from the Falcon aircraft.

chemical measurements shows that, in all three cases presented, the CSCTM was successful in reasonably representing observed $\mathrm{CO}$ and $\mathrm{CO}_{2}$ mixing ratios.

The GEOS-5 SCM was used to simulate the selected storms using initial condition and forcing profiles of temperature, moisture, and trace gas mixing ratios computed by averaging over an area in the CRM domain comparable in size to a GCM grid cell. When default parameter values were used in the moist physics schemes, the SCM significantly underestimated convective mass flux relative to the CRMs, which resulted in weaker transport of trace gases. SCM simulations performed with and without advective tendencies showed that the impact of horizontal and vertical advective tendencies on trace gas profiles was relatively small. Salzmann et al. (2004) studied the impact of vertical large-scale advection of tracers in multiday CRM simulations. Significant differences were found to result from the inclusion of these tendencies after $24 \mathrm{~h}$. However, their results suggest relatively small changes in tracer profiles in the early hours of the simulation. Because the simulations presented here are much shorter (from 3 to $4 \mathrm{~h}$ ), we believe our results are consistent with Salzmann et al. If these simulations were carried out over multiday periods, the impact of the large-scale advective tendencies of tracers would likely grow.
Clouds in the SCM were shallower than in the CRMs, which has been noted in several previous studies. Pickering et al. (1995) compared convective mass fluxes produced by the GEOS-1 data assimilation system employing the RAS convective scheme with fluxes from a 2D GCE simulation of a large squall line observed over Oklahoma during the Preliminary Regional Experiment for Storm-scale Operational and Research Meteorology (PRE-STORM) campaign. Although the magnitudes of the profiles were similar, the GCE simulation produced greater mass flux at upper levels. Park et al. (2001) used a single-column chemical transport model driven with GEOS-1 convective mass fluxes to study the convective transport of ozone precursors. The transport of $\mathrm{CO}$ during the PRE-STORM squall line was compared with 2D CRM results from Pickering et al. (1992) and showed that the altitude of maximum $\mathrm{CO}$ mixing ratios in the upper troposphere was $2 \mathrm{~km}$ lower in the SCM than in the CRM, though no chemical observations were available to verify either simulation. Donner et al. (2007) examined the transport of radon-222 and methyl iodide in a GCM using two different convective schemes, one of which was a modified version of RAS and the other, described in Donner (1993), represents convection as an ensemble of entraining plumes with associated mesoscale updrafts and downdrafts. The mesoscale motions and 

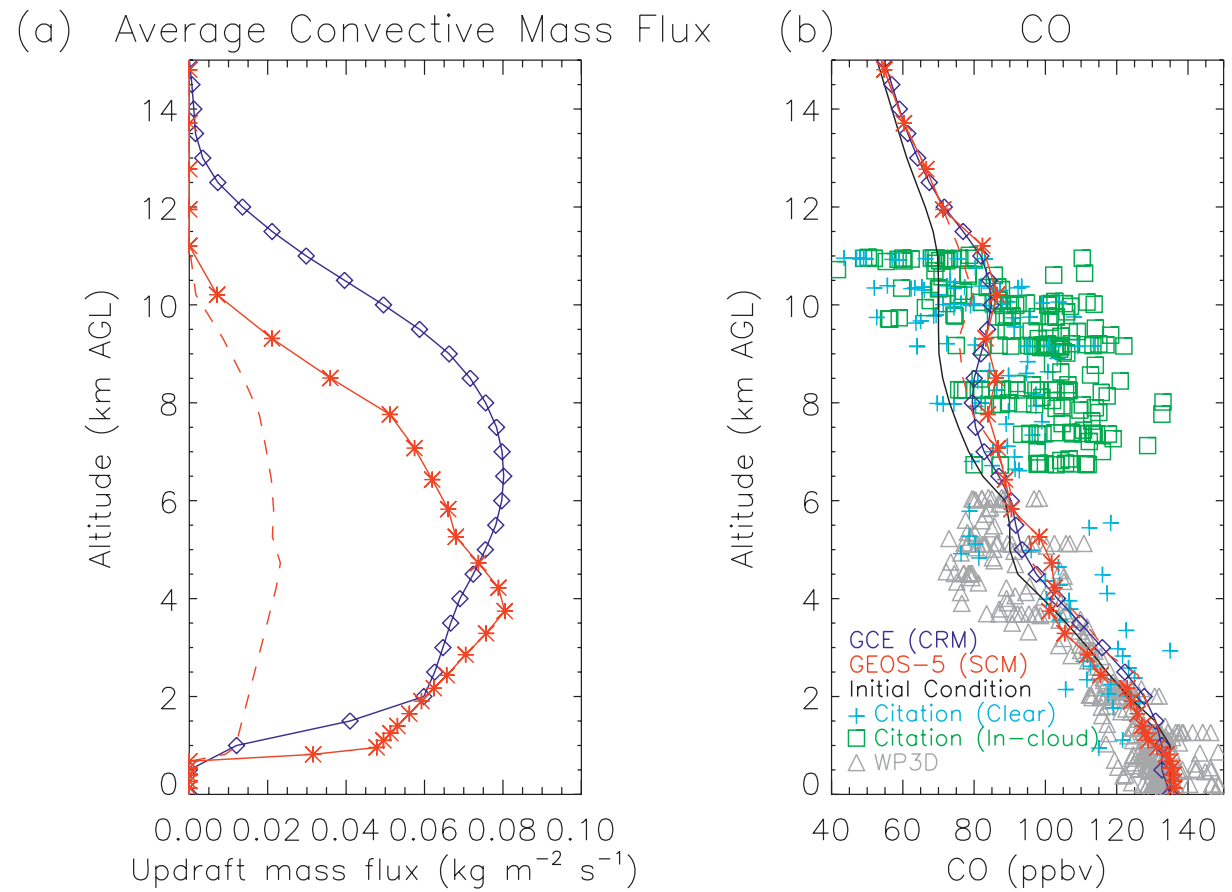

FIG. 9. As in Fig. 8 but for the 10 Jul STERAO storm with (b) simulated CO mixing ratios compared with observations from the Citation and WP3D aircraft.

plume vertical-velocity dynamics included in the second parameterization allowed convective systems to overshoot the level of neutral buoyancy, transporting both species to greater altitudes than RAS, which only allows plumes to reach the level of neutral buoyancy.

This work also presents an adaptation of a statistical technique for examining parameter sensitivity from earlier work by Liu et al. (2004), which identified the most significant parameters affecting ground temperature and surface fluxes in a coupled land-atmosphere SCM. This is the first study to examine the impact of parameter sensitivity on vertical trace gas distributions. The RSA identified five parameters as sensitive in all three case studies. These parameters affect the relaxation time scale in the RAS convective scheme, the amount of falling precipitation evaporated into the environment, the autoconversion of convective condensate, and the critical value of the cloud work function. The results show that alterations to parameter settings can substantially improve the comparison between SCM and CRM convective mass flux. Modified parameter settings also improved the comparison between upper tropospheric trace gas mixing ratios in the SCM and CRM simulations of the STERAO and CRYSTALFACE storms. However, parameter settings do not affect the depth of convective systems, which results in detrainment at lower altitudes in the SCM than in the CRM. In the EULINOX storm, differences in the en- trainment and detrainment levels between the CRM and SCM simulations resulted in poorer agreement between the models when the mass flux comparison was improved by modified parameter settings.

These results demonstrate that parameter settings exert a strong influence over mass fluxes produced by a single convective parameterization. Consequently, the choice of parameter values plays a significant role in determining trace gas mixing ratios in the upper troposphere. Folkins et al. (2006) studied cloud mass fluxes produced by different convective schemes used in several 3D GCMs, a SCM, and a two-column model. They found that the range of mass fluxes below $6 \mathrm{~km}$ produced by two different implementations of RAS was greater than the range of fluxes from the four other convective schemes evaluated. These results suggest that mass flux profiles are also strongly sensitive to differences in the implementation of a single convective scheme.

The methods presented here have a number of limitations that should be noted. Although the CRM simulations have been demonstrated to reasonably represent the dynamical and physical evolution of the observed convective events, they are not a perfect representation of reality. Because convective mass flux is not an observable quantity, comparison with CRM calculated mass flux remains one of the only ways to evaluate the mass fluxes generated by convective parameterizations employed in GCMs. Although convective mass flux 
(a) Average Convective Mass Flux (b)

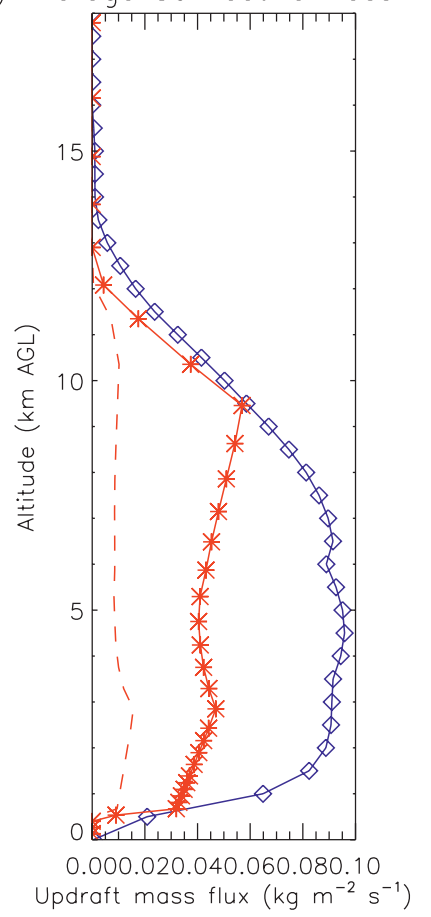

$\mathrm{CO}$

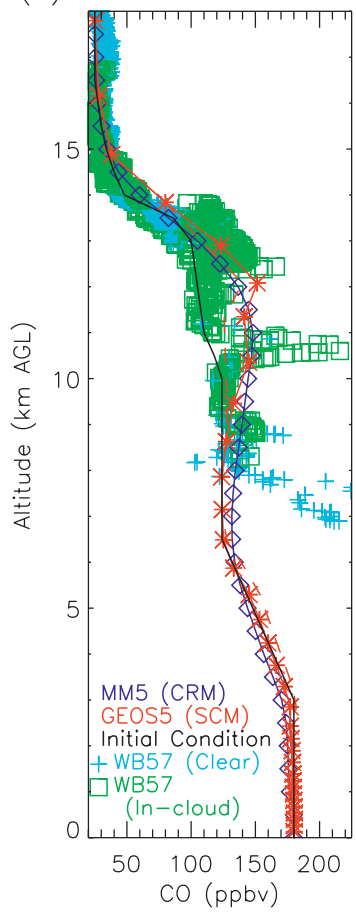

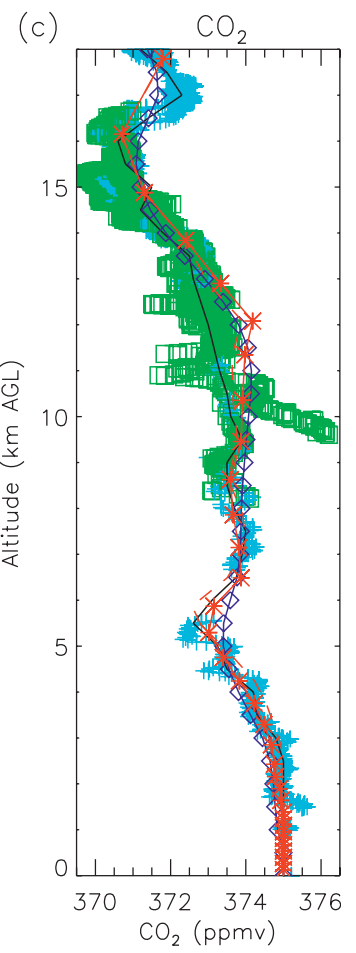

FIG. 10. Vertical profiles of (a) convective mass flux, (b) $\mathrm{CO}$, and (c) $\mathrm{CO}_{2}$ from CRM (blue) and SCM (red) simulations of the 3 Jul CRYSTAL-FACE storm. Red lines as in Fig. 8. Mass flux profiles are averaged over 210 min; $\mathrm{CO}$ and $\mathrm{CO}_{2}$ mixing ratios are calculated at the end of the 4-h simulations and compared with observations from the WB57 aircraft.

in CRMs and SCMs has been compared in a number of studies, we are aware of no examples in the literature of this approach being extended to examine trace gas profiles. The comparison of trace gas profiles is critically important because the method of transport in CRMs and SCMs differs in addition to differences in calculated mass flux. Whereas SCMs and GCMs calculate tracer transport using a mass flux-based approach, CRMs transport gases using resolved small-scale motions. Comparing trace gas profiles adds complexity because initial profiles of the gases must be constructed and the CRMs incloud performance evaluated using aircraft observations that are limited in spatial and temporal availability. Because aircraft observations are the only way to reliably observe the vertical redistribution of trace gases within clouds, this complexity is a necessary component of evaluating SCM performance of convective transport.

This work also presents the first attempt to examine the impact of convective parameter sensitivity on convective mass flux and trace gas profiles employing a method primarily used in land surface models. The results demonstrate that trace gas and convective mass flux profiles are strongly impacted by parameter settings. While this finding is likely true in many models, the magnitude of this effect may differ due to the wide range of implementations of convective parameterizations in different GCMs. Owing to such implementation differences, the results presented here regarding the sensitivity and values of specific parameters cannot reasonably be generalized beyond the GEOS-5 framework. Additionally, the results presented here based on three case studies are not sufficient for the purposes of tuning any GCM, including GEOS-5. We do hope that the sensitivity demonstrated here will encourage other modeling groups to consider including trace gases in future experiments as they may provide valuable information on atmospheric circulation.

Perturbations to parameters that have been shown to exert the greatest control over convective transport will be used to construct an ensemble of global simulations representing the uncertainty introduced into simulated trace gas distributions by convective schemes. Further investigation of the depth of convection in the GCM is also needed. This is especially significant because convective transport strongly influences the composition of the upper troposphere and lower stratosphere. Future GCM studies of long-range pollution transport and climate change will be affected by the ability of convective parameterizations to realistically reproduce the depth 
of observed convection, as well as its intensity and location.

Despite some limitations, this approach offers new possibilities. Meteorological fields are relatively insensitive to many parameters used in the GCM, meaning there is often substantial leeway in setting these values. This study demonstrates that trace gases show sensitivity to convective parameters, thus yielding an additional observational constraint. Future field and satellite campaigns that gather information on the vertical distributions of trace gases will provide the opportunity to use trace gas observations to improve the representation of convective processes in global models.

Acknowledgments. Lesley Ott was supported through an ORAU postdoctoral fellowship. SCM research was funded by NASA's MAP program as part of a study to understand the distribution and transport of carbon species in the environment using GEOS-5. We thank Michele Rienecker for her support and encouragement to perform this research in the GMAO. CRM studies were supported under National Science Foundation Grants ATM9912336 and ATM0004120 and NASA Grant NAG5-11276. We thank Wei-Kuo Tao of NASA GSFC for supplying the 3D GCE model and Alex DeCaria of Millersville University for assistance with the CSCTM. The EULINOX project was funded by the European Commission (Research DG) through the Environment and Climate program (Contract ENV4CT97-0409). We thank the EULINOX team that carried out the airborne measurements (Schlager et al., DLR). We would also like to thank Karsten Baumann for providing observational data from the STERAO campaign and Yansen Wang, formerly of UMBC/JCET and currently at the US Army Research Center in Adelphi, MD, for providing the MM5 simulation of the 3 July CRYSTAL-FACE storm.

\section{REFERENCES}

Arakawa, A., and W. H. Schubert, 1974: Interaction of a cumulus cloud ensemble with the large-scale environment, Part I. $J$. Atmos. Sci., 31, 674-701.

Bacmeister, J. T., cited 2005: GEOS-5 SYSTEM: Moist physics parameterizations. [Available online at http://gmao.gsfc.nasa. gov/systems/geos5/STRUCTURE/AGCM/Moist.php.]

_- M. J. Suarez, and F. R. Robertson, 2006: Rain reevaporation, boundary layer-convection interactions, and Pacific rainfall patterns in an AGCM. J. Atmos. Sci., 63, 3383-3403.

Barth, M. C., S.-W. Kim, W. C. Skamarock, A. L. Stuart, K. E. Pickering, and L. E. Ott, 2007a: Simulations of the redistribution of formaldehyde, formic acid, and peroxides in the 10 July 1996 Stratospheric-Tropospheric Experiment: Radiation, Aerosols, and Ozone deep convection storm. J. Geophys. Res., 112, D13310, doi:10.1029/2006JD008046.
- and Coauthors, 2007b: Cloud-scale model intercomparison of chemical constituent transport in deep convection. Atmos. Chem. Phys., 7, 4709-4731.

Bastidas, L. A., H. V. Gupta, S. Sorooshian, W. J. Shuttleworth, and Z. L. Yang, 1999: Sensitivity analysis of a land surface scheme using multicriteria methods. J. Geophys. Res., 104, 19 481-19 490.

Bechtold, P., and Coauthors, 2000: A GCSS intercomparison for a tropical squall line observed during TOGA COARE. II: Intercomparison of single-column models and a cloud-resolving model. Quart. J. Roy. Meteor. Soc., 126, 865-888.

Bey, I., D. J. Jacob, J. A. Logan, and R. M. Yantosca, 2001: Asian chemical outflow to the Pacific: Origins, pathways, and budgets. J. Geophys. Res., 106, 23 097-23 113.

DeCaria, A. J., 2000: Effects of convection and lightning on tropospheric chemistry studied with cloud, transport, and chemistry models. Ph.D. dissertation, University of Maryland, College Park, 169 pp.

, K. E. Pickering, G. L. Stenchikov, and L. E. Ott, 2005: Lightning-generated $\mathrm{NO}_{\mathrm{X}}$ and its impact on tropospheric ozone production: A three-dimensional modeling study of a Stratosphere-Troposphere Experiment: Radiation, Aerosols, and Ozone (STERAO-A) thunderstorm. J. Geophys. Res., 110, D14303, doi:10.1029/2004JD005556.

Dickerson, R. R., and Coauthors, 1987: Thunderstorms: An important mechanism in the transport of air pollutants. Science, 235, 460-465.

Donner, L. J., 1993: A cumulus parameterization including mass fluxes, vertical momentum dynamics, and mesoscale effects. J. Atmos. Sci., 50, 889-906.

, L. W. Horowitz, A. M. Fiore, C. J. Seman, D. R. Blake, and N. J. Blake, 2007: Transport of radon-222 and methyl iodide by deep convection in the GFDL global atmospheric model AM2. J. Geophys. Res., 112, D17303, doi:10.1029/ 2006JD007548.

Dye, J. E., and Coauthors, 2000: An overview of the Stratospheric-Tropospheric Experiment: Radiation, Aerosols, and Ozone (STERAO) deep convection experiment with results for the July 10, 1996 storm. J. Geophys. Res., 105, $10023-10045$.

Fehr, T., H. Höller, and H. Huntrieser, 2004: Model study on production and transport of lightning-produced $\mathrm{NO}_{\mathrm{x}}$ in a EULINOX supercell storm. J. Geophys. Res., 109, D09102, doi:10.1029/2003JD003935.

Folkins, I., and Coauthors, 2006: Testing convective parameterizations with tropical measurements of $\mathrm{HNO}_{3}, \mathrm{CO}, \mathrm{H}_{2} \mathrm{O}$, and $\mathrm{O}_{3}$ : Implications for the water vapor budget. J. Geophys. Res., 111, D23304, doi:10.1029/2006JD007325.

Gregory, D., and M. J. Miller, 1989: A numerical study of the parametrization of deep tropical convection. Quart. J. Roy. Meteor. Soc., 115, 1209-1241.

Höller, H., and U. Schumann, Eds., 2000: EULINOX-The European Lightning Nitrogen Oxides Project. Tech. Rep. DLR-FB 2000-28, Deutsches Zentrum für Luft- und Raumfahrt, 240 pp.

,- H. Huntrieser, C. Feigl, C. Théry, P. Laroche, U. Finke, and J. Seltmann, 2000: The severe storms of 21 July 1998-Evolution and implications for $\mathrm{NO}_{\mathrm{X}}$ production. EULINOX-The European Lightning Nitrogen Oxides Experiment, Tech. Rep. DLR-FB 2000-28, Deutsches Zentrum für Luft- und Raumfahrt, 109-128.

Hornberger, G. M., and R. C. Spear, 1981: An approach to the preliminary analysis of environmental systems. J. Environ. Manage., 12, 7-18. 
Huntrieser, H., and Coauthors, 2002: Airborne measurements of NOx, tracer species, and small particles during the European Lightning Nitrogen Oxides Experiment. J. Geophys. Res., 107, 4113, doi:10.1029/2000JD000209.

Klemp, J. B., and R. B. Wilhelmson, 1978: The simulation of three-dimensional convective storm dynamics. J. Atmos. Sci., 35, 1070-1096.

Liu, Y., H. V. Gupta, S. Sorooshian, L. A. Bastidas, and W. J. Shuttleworth, 2004: Exploring parameter sensitivities of the land surface using a locally coupled land-atmosphere model. J. Geophys. Res., 109, D21101, doi:10.1029/2004JD004730.

Lock, A. P., A. R. Brown, M. R. Bush, G. M. Martin, and R. N. B. Smith, 2000: A new boundary layer mixing scheme. Part I: Scheme description and single-column model tests. Mon. Wea. Rev., 128, 3187-3199.

Loewenstein, M., and Coauthors, 2003: Biomass burning signatures in CO observed during CRYSTAL-FACE. Proc. CRYSTALFACE Science Team Meeting, Salt Lake City, UT, NASA, 2-17. [Available online at http://www.espo.nasa.gov/crystalface/ presentations_files/Posters/2-17_Loewenstein.pdf.]

Lopez, J. P., and Coauthors, 2006: CO signatures in subtropical convective clouds and anvils during CRYSTAL-FACE: An analysis of convective transport and entrainment using observations and a cloud-resolving model. J. Geophys. Res., 111, D09305, doi:10.1029/2005JD006104.

Louis, J.-F., 1979: A parametric model of vertical eddy fluxes in the atmosphere. Bound.-Layer Meteor., 17, 187-202.

Luo, Y., S. K. Krueger, and K.-M. Xu, 2006: Cloud properties simulated by a single-column model. Part II: Evaluation of cumulus detrainment and ice-phase microphysics using a cloud-resolving model. J. Atmos. Sci., 63, 2831-2847.

Madronich, S., 1987: Photodissociation in the atmosphere: 1. Actinic fluxes and the effects of ground reflections and clouds. $J$. Geophys. Res., 92, 9740-9752.

Moorthi, S., and M. J. Suarez, 1992: Relaxed Arakawa-Schubert: A parameterization of moist convection for general circulation models. Mon. Wea. Rev., 120, 978-1002.

Ott, L. E., K. E. Pickering, G. L. Stenchikov, H. Huntrieser, and U. Schumann, 2007: Effects of lightning NOx production during the 21 July European Lightning Nitrogen Oxides Project storm studied with a three-dimensional cloud-scale chemical transport model. J. Geophys. Res., 112, D05307, doi:10.1029/ 2006JD007365.

Park, R. J., G. L. Stenchikov, K. E. Pickering, R. R. Dickerson, D. J. Allen, and S. Kondragunta, 2001: Regional air pollution and its radiative forcing: Studies with a single-column chemical and radiation transport model. J. Geophys. Res., 106, 28 751-28 770.

Pickering, K. E., A. M. Thompson, J. R. Scala, W.-K. Tao, R. R. Dickerson, and J. Simpson, 1992: Free tropospheric ozone production following entrainment of urban plumes into deep convection. J. Geophys. Res., 97, 17 985-18 000.

, - - W.-K. Tao, R. B. Rood, D. P. McNamara, and A. M. Molod, 1995: Vertical transport by convective clouds: Comparisons of three modeling approaches. Geophys. Res. Lett., 22, 1089-1092.

_ , and Coauthors, 1996: Convective transport of biomass burning emissions over Brazil during TRACE A. J. Geophys. Res., 101, 23 993-24 012.

Redelsperger, J. L., and Coauthors, 2000: A GCSS model intercomparison for a tropical squall line observed during TOGA COARE. 1. Cloud-resolving models. Quart. J. Roy. Meteor. Soc., 126, 823-863.

Ridley, B. A., and Coauthors, 2004: Florida thunderstorms: A faucet of reactive nitrogen to the upper troposphere. J. Geophys. Res., 109, D17305, doi:10.1029/2004JD004769.

Rienecker, M. M., and Coauthors, 2007: The GEOS-5 Data Assimilation System: Documentation of versions 5.0.1 and 5.1.0. NASA Tech. Doc. NASA/TM-2007-104606, Vol. 27, 95 pp. [Available online at http://gmao.gsfc.nasa.gov/pubs/docs/ GEOS-5.0.1_Documentation_r3.pdf.]

Ryan, B. F., and Coauthors, 2000: Simulations of a cold front by cloud-resolving, limited-area, and large-scale models, and a model evaluation using in situ and satellite observations. Mon. Wea. Rev., 128, 3218-3235.

Salzmann, M., M. G. Lawrence, V. T. J. Phillips, and L. J. Donner, 2004: Modelling tracer transport by a cumulus ensemble: Lateral boundary conditions and large-scale ascent. Atmos. Chem. Phys., 4, 1797-1811.

Simpson, J., and V. Wiggert, 1969: Models of precipitating cumulus towers. Mon. Wea. Rev., 97, 471-489.

Skamarock, W. C., and Coauthors, 2000: Numerical simulations of the July 10 Stratospheric-Tropospheric Experiment: Radiation, Aerosols, and Ozone/Deep Convection Experiment convective system: Kinematics and transport. J. Geophys. Res., 105, 19 973-19 990.

_ J. E. Dye, E. Defer, M. C. Barth, J. L. Stith, B. A. Ridley, and K. Baumann, 2003: Observational- and modeling-based budget of lightning-produced $\mathrm{NO}_{\mathrm{x}}$ in a continental thunderstorm. J. Geophys. Res., 108, 4305, doi:10.1029/2002JD002163.

Stenchikov, G., and Coauthors, 1996: Stratosphere-troposphere exchange in a mid-latitude mesoscale convective complex. 2. Numerical simulations. J. Geophys. Res., 101, 6837-6851.

—, K. Pickering, A. DeCaria, W.-K. Tao, J. Scala, L. Ott, D. Bartels, and T. Matejka, 2005: Simulation of the fine structure of the 12 July 1996 Stratosphere-Troposphere Experiment: Radiation, Aerosols and Ozone (STERAO-A) storm accounting for effects of terrain and interaction with mesoscale flow. $J$. Geophys. Res., 110, D14304, doi:10.1029/2004JD005582.

Strahan, S. E., A. R. Douglass, J. E. Nielsen, and K. A. Boering, 1998: The $\mathrm{CO}_{2}$ seasonal cycle as a tracer of transport. $J$. Geophys. Res., 103, 13 729-13 741.

Tao, W.-K., and J. Simpson, 1993: Goddard Cumulus Ensemble Model Part I: Model description. Terr. Atmos. Oceanic Sci., 4, 35-72.

— , and Coauthors, 2003a: Microphysics, radiation and surface processes in the Goddard Cumulus Ensemble (GCE) model. Meteor. Atmos. Phys., 82, 97-137.

_ dard Space Flight Center. Recent Res. Dev. Atmos. Sci., 2, 1-52.

Tompkins, A. M., 2002: A prognostic parameterization for the subgrid-scale variability of water vapor and clouds in largescale models and its use to diagnose cloud cover. J. Atmos. Sci., 59, 1917-1942.

Waliser, D. E., J. A. Ridout, S. Xie, and M. Zhang, 2002: Variational objective analysis for atmospheric field programs: A model assessment. J. Atmos. Sci., 59, 3436-3456.

Xu, K.-M., 1995: Partitioning mass, heat, and moisture budgets of explicitly simulated cumulus ensembles into convective and stratiform components. J. Atmos. Sci., 52, 551-573.

- and A. Arakawa, 1992: Semiprognostic tests of the ArakawaSchubert cumulus parameterization using simulated data. $J$. Atmos. Sci., 49, 2421-2436.

-, and D. A. Randall, 1996: A semiempirical cloudiness parameterization for use in climate models. J. Atmos. Sci., 53, 3084-3102.

Zhu, Y., and R. Gelaro, 2008: Observation sensitivity calculations using the adjoint of the Gridpoint Statistical Interpolation (GSI) analysis system. Mon. Wea. Rev., 136, 335-351. 